\title{
A BUILDING AS A BIOGRAPHY: I.M. PEI AND HIS SUZHOU MUSEUM
}

A thesis presented to the Department of Architectural History

\author{
University of Virginia \\ In Partial Fulfillment \\ of the Requirements for the Degree \\ Master of Architectural History
}

By

Chenying Huang

(B.A., Fudan University, 2012)

May 2014

Committee Members:

Sheila Crane, Chair

Richard Guy Wilson

Shiqiao Li 


\section{Table of Contents}

$\begin{array}{ll}\text { List of Illustrations } & \text { i }\end{array}$

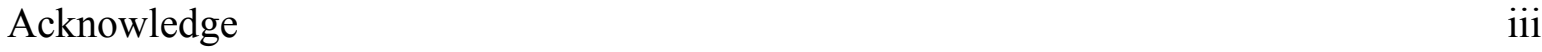

$\begin{array}{ll}\text { Introduction } & 1\end{array}$

Chapter 1 I.M. Pei's Return to Suzhou 11

- The Chinese Root

- The Project Background

Chapter 2 The Design Method

- Catching the Essence

- The Problematic Method

Chapter 3 Building as a Biography

- Pei's Signature

- The New Suzhou Rockery

$\begin{array}{ll}\text { Conclusion } & 48\end{array}$

Appendix A: Site map of Suzhou

Appendix B: Site map of Suzhou Museum $\quad 52$

Appendix C: Axonometric CAD Drawing, Southeast 53

Appendix D: Site Plan CAD Drawing $\quad 54$

$\begin{array}{ll}\text { Bibliography } & 55\end{array}$

$\begin{array}{ll}\text { Illustrations } & 58\end{array}$ 


\section{Illustrations}

1. "I.M. Pei receives the Royal Gold Metal for architecture," Dezeen Magazine, http://www.dezeen.com/2010/02/11/i-m-pei-receives-the-royal-gold-medal-for-architecture/ (accessed March 2, 2014)

2. Jianxi Lin, "Skyline View of old inner city of Suzhou from Baoen Pagoda," Jianxi Lin's Blog, 2012, http://blog.wenxuecity.com/myblog/57811/201304/24625.html (accessed April 28, 2014)

3. "Lion Grove Garden," Suzhou, China, 2011. Photograph by author.

4. Cannell, Michael T., "As the apotheosis of Western glamour, the Park Hotel aroused Ieoh Ming's first interest in architecture," I.M. Pei : Mandarin of Modernism. 1st ed. New York: Carol Southern Books, 1995, 60.

5. Cannell, Michael T., "Walter Gropius standing over Pei's desk, Pei was a slightly skeptical acolyte," I.M. Pei : Mandarin of Modernism. 1st ed. New York: Carol Southern Books, 1995, 72.

6. Cannell, Michael T., "In his Harvard thesis a Shanghai art museum, Pei tried to show that the modern style could accommodate local variation," I.M. Pei : Mandarin of Modernism. 1st ed. New York: Carol Southern Books, 1995, 85.

7. "Entrance of the Prince Zhong's Mansion," Suzhou, China, 2013. Photograph by author.

8. "Exhibitions in the Prince Zhong's Mansion," Suzhou, China, 2013. Photograph by author.

9. Xin Zhang and Suzhou bo wu guan, "Map of Pingjiang, Song Dynasty urban plan," Suzhou Museum. Beijing; London: Great Wall Publishers; In collaboration with London Editions, 2007, 8 .

10. Xin Zhang and Suzhou bo wu guan, "Beauty of harmony," Suzhou Museum. Beijing; London: Great Wall Publishers; In collaboration with London Editions, 2007, 29.

11. "Entrance of the Suzhou Museum," Suzhou, China, 2013. Photograph by author.

12. Philip Jodidio and Janet Adams Strong, "The main body of the museum as seen from behind the central pond," I.M. Pei : Complete Works (New York: Rizzoli, 2008), 314.

13. Xin Zhang and Suzhou bo wu guan, "The lobby," Suzhou Museum. Beijing; London: Great Wall Publishers; In collaboration with London Editions, 2007, 33.

14. Philip Jodidio and Janet Adams Strong, "Fragrant Hill Hotel, Garden façade," I.M. Pei : Complete Works (New York: Rizzoli, 2008), 181. 
15. "Traditional Eave of the Prince Zhong's Masion,” Suzhou, China, 2013. Photograph by author.

16. Walkway between Suzhou Museum and the ancient structures, Suzhou, China, 2013.

Photograph by author.

17. Xin Zhang and Suzhou bo wu guan, "Beauty of contrast," Suzhou Museum. Beijing; London: Great Wall Publishers; In collaboration with London Editions, 2007, 29.

18. Philip Jodidio and Janet Adams Strong, "The main entrance of the Museum of the Islamic Art," I.M. Pei : Complete Works (New York: Rizzoli, 2008), 330.

19. Philip Jodidio and Janet Adams Strong, "The pure lines and cantilevered forms of the Oare Tea Pavilion,” I.M. Pei : Complete Works (New York: Rizzoli, 2008), 306.

20. Philip Jodidio and Janet Adams Strong, "Miho Museum, the entrance lobby area with Pei's favored Magny Doré cladding," I.M. Pei : Complete Works (New York: Rizzoli, 2008), 273.

21. Chinoiserie Teahouse, Sanssouci Summer Palace, Potsdam, Germany, 2005. Photograph by author.

22. Philip Jodidio and Janet Adams Strong, "Suzhou Museum garden," I.M. Pei : Complete Works (New York: Rizzoli, 2008).

23. Pei Partnership Architects, "Axonometric View of Tea Pavilion,” 2003, CAD drawing, Pei Partnership Architects Library, New York City.

24. "Suzhou Museum interior," Suzhou, China, 2011. Photograph by author.

25. "Suzhou Museum roof structure," Suzhou, China, 2013. Photograph by author.

26. “Suzhou Museum Ting structure,” Suzhou, China, 2013. Photograph by author.

27. Mi Fu. "Auspicious Pines in Spring Mountains." Chinaonlinemuseum.com, http://www.chinaonlinemuseum.com/painting-mi-fu-auspicious-pines.php (accessed March 2, 2014)

28. Philip Jodidio and Janet Adams Strong, "The sliced-rock design at the back of the pond," I.M. Pei : Complete Works (New York: Rizzoli, 2008), 324.

29. "The rockery design at night," Postcard of the Suzhou Museum. Author's collection.

30. “Japanese Rock Garden-Karesansui," Kusuyama Japan Fine Crafts, http://www.kusuyama.jp/blog/japanese-rock-garden-karesansui/ (accessed April 28, 2014) 


\section{Acknowledgements}

I would like to express my sincere gratitude to several people for their generous support throughout my research. First, I would like to thank Sheila Crane for her encouragement of the initial topic during the first semester of my studies. It was under her direction that this thesis was completed. I've appreciated her input, advice, and enthusiasms that lead me fully explore I.M. Pei's design of the Suzhou Museum. I would also like to thank Richard Guy Wilson, whose knowledge, suggestions and encouragement has been an invaluable contribution to my research. Thank you to Shiqiao Li, whose insight, challenge and encouragement pushed me to construct a more critical reading of Pei's work. I'd also like to thank Yunsheng Huang for his valuable advices in the East meets West class.

I owe a huge debt of gratitude to Sandi Pei, son of I.M. Pei, one of the founding partners of the Pei Partnership Architects. It is due to his efforts that I have had a clear understanding of I.M. Pei's original design for his Suzhou Museum and had access to the project archives and drawings. I would like to thank Karen Van Lengen for kindly sharing her stories and knowledge of I.M. Pei with me and introducing me to Sandi Pei. I learnt the methods of reading cultural landscape from Beth Meyer. I am grateful for her encouragement of my thesis topic.

I owe a special thanks to my parents, who have provided continuous support and have always encouraged me to follow my passion. I would also like to thank my relatives in Shanghai and Suzhou, my biological family hometown, for their warmly supports of my research. A big thanks to $\mathrm{Yu} \mathrm{Gu}$ for helping me collecting resources from Chinese journals. Finally I would like to thank my fellow classmates, whose passion, support and unique perspectives have made my graduate school experience unforgettable. 


\section{Introduction}

Ieoh Ming Pei (Figure 1), an illustrious architect of the twentieth century, has created many cross-cultural projects, such as his most famous design, the Grand Louvre and his more resent the Museum of Islamic Art at Doha. His distinctive identity—as an American architect born in China-gives him a special transnational background, which has attracted the attention of scholars from both eastern and western parts of the world. Almost every published interview with Pei mentions the influence of his Chinese origin. Scholars typically try to locate his design inspirations in his childhood memories, connecting Pei with his dual-cultural background and describing his buildings based on his biography.

Suzhou, the town where Pei family was located, is often mentioned by scholars as a way to understand I.M. Pei's Chinese cultural background. The city is located in Jiangsu Province in the south east coast of China near Shanghai. It is famous for its architecture and landscape, especially its ancient gardens. Suzhou gardens are dynamic combinations of landscape and architecture. Spanning from the Northern Song to the Qing dynasties, most of the Suzhou gardens were built by scholars. Suzhou gardens reflect many key features of classical Chinese garden design. Its constructed landscapes mimicked natural scenery, such as rocks, hills and rivers, as well as strategically located pavilions and pagodas. The gardens of Suzhou are viewed as a category of fine arts in China, an expression of ancient Chinese scholars' poetic pursuits and their understanding of life and nature. The Suzhou Museum is a museum of ancient Chinese art, 
ancient Chinese paintings, calligraphy, and handmade crafts, located next to the most famous garden-Zhuozheng Garden. I.M. Pei designed the current building of the Suzhou Museum in association with Pei Partnership Architects. It was inaugurated in October 2006.

Suzhou Museum provides a special opportunity to think critically about Pei's cross-cultural designs, particularly in relation to his biography. This thesis originated my final project for the Method in Architectural History class, during which I completed a historiographical study of the Suzhou Museum and developed an interest in the biographical organization of architectural history. The debate around the Suzhou Museum is intriguing and distinctive. Here too scholars emphasized Pei's cultural background as a mean of defining the cultural identity of the Suzhou museum. Some scholars think the museum is designed in a specifically "Chinese style," given its physical forms and the details of its design. On the contrary, others view this museum as an "inappropriate" modern design that contrasts too sharply with the surrounding traditional gardens. They argue that this museum failed to express Chinese culture both in details and sensorial presentation. However, most of the sources judge the building based only on what they can see, which was quite superficial, and only a few of those papers involve analyses of the archives and building processes. By studying the processes of Pei's design for the Suzhou Museum, this thesis intends to depart from the "Chinese or not" debate and argue that the Suzhou Museum is a distinctive representation of I.M. Pei’s dual-cultural biography.

The first chapter of this thesis will analyze I.M. Pei's "problematic" dual-cultural biography. 
Pei's ancestors have a long family history in the city of Suzhou dating back to the Ming Dynasty. Pei was born in Guangzhou into an upper class banker's family in 1917. He moved to Shanghai after his father's business changed and lived there for several years. During his time in Shanghai, Pei spent some summers in Suzhou with his grandfather and developed his interest in architecture design. Even though his architectural education and subsequent practice were centered in America, his Chinese upbringing seems to be deeply imprinted in his biography. People are interested in how his childhood influenced his designs and in his dual-cultural identity. At the beginning of the twenty-first century, Pei finally had a chance to retrieve his Suzhou memories, by designing the new Suzhou Museum. The chapter will introduce the historical background of the Suzhou Museum project. A site analysis is also included in order to provide readers a clear understanding of the specific location of the new museum project in relationship to the city of Suzhou as well as Pei's ancestors' family.

An analysis of Pei's design of the Suzhou Museum is presented in the second chapter. One of Pei's distinctive design methods will be introduced, which I refer to as the "Key Features" method. Pei wants his cultural projects, such as museums, to express the spirit of the culture in which they are located. To achieve his goal, Pei focuses on identifying the essence of the site's historical architecture. In Suzhou, Pei was attracted to the geometrical rhythm of the city's landscape that is composed of the traditional gabbled roofs (Figure 2), and he considered this roof profile to be the essence of Suzhou architecture. The chapter further discusses Pei's work 
abstracting on the Suzhou profile into a simplified geometrical expression of forty-five degree angles, which he adapted for the Suzhou Museum. The chapter will argue that even though Pei and his colleagues believed their method allowed the new museum to fit into the existing landscape, this "Key Features" method was far expressing the spirit of Suzhou. The result was superficial and was actually more a product of Pei's educational background in western modern architecture.

The third and final chapter addresses the details of the Suzhou Museum's design, including the plan, the structure, and the plants, etc. The design details were not only inspired by the traditional Suzhou gardens, but also were borrowed from Pei's former projects and even were developed from his romantic memory of his hometown. With the wisteria transplanted from the ancient garden, the shoji roof screen borrowed from Miho Museum, and the "uncanny" rockery landscape abstracted from Mifu's painting, the Suzhou Museum became a mixture of different cultures, of the east and the west. These aspects of the design revealed Pei's ambition of to create a modern Suzhou style in an attempt to negotiate his own Suzhou roots.

Although Pei wished to inspired young architects in China by designing a modern building with a traditional spirit, the Suzhou Museum project as a expressed his own biography and his cross-cultural experiences. This thesis argues that the Suzhou Museum project was product of Pei's reconstructed Suzhou identity. It was shaped by Pei's attempt to recapture his childhood experiences. 


\section{Historiography}

The argument of this thesis engaged two main bodies of scholarship: commentators who emphasizes the modern style of Pei's designs for the Suzhou Museum and those who believe the new Suzhou Museum is very Chinese, but also who criticize Pei's representation of Suzhou architecture. Mr. Sandi Pei and the Pei Partnership Architect provided a wealth of materials regarding Mr. I.M. Pei's design ideas and the project's details ${ }^{1}$. Primary sources, including an interview with Sandi Pei, the original CAD drawings for the museum, and museum publications were crucial to understanding the project's developing process and Pei's original design intention. Additional published conversations with I.M. Pei and documentary films of his projects were also consulted for information on Pei's dual-cultural identity and his cross-cultural designs.

The biography I.M. Pei: Mandarin of Modernism published in 1995 by Michael Cannell provides rich details of Pei's life experiences. Cannell is a former editor of The New York Times. He collected primary information about I.M. Pei from Pei's family, partners, clients and scholars. The biography is a vivid portrait of Pei. The author is extremely interested in Pei's dual-cultural identity and called his book "a tale of East and West." ${ }^{2}$ Although the book does not include

\footnotetext{
${ }^{1}$ Lizhong (Sandi) Pei. Interviewed by Huang Chenying. Personal interview. New York City, October 24, 2013. The collection of original CAD drawings was provided by Pei Partnership Architects Library, New York City.

2 Michael T. Cannell, I.M. Pei : Mandarin of Modernism, 1st ed. (New York: Carol Southern Books, 1995).
} 
materials on the Suzhou Museum project, it is still an inspiring presentation of Pei.

The official museum guidebook in English, Suzhou Museum (Suzhou Bo Wu Guan), was written by Xin Zhang in cooperation with the Suzhou Museum and published in 2007, a year after the museum opened ${ }^{3}$. It offers readers the general background of the city of Suzhou and the development of the Suzhou Museum while also introduces I.M. Pei and his design for the new museum. The third chapter, "I.M. Pei and the Suzhou Museum," focuses primarily on presenting different aspects of the project that the author insists reveal a distinctly Chinese spirit. Similarly, Ning $\mathrm{Xu}$ and Xiaoying Ni, two local journalists who followed and reported the construction of the new Suzhou Museum from the project's beginning, published I.M. Pei and Suzhou Museum (Bei Yuming Yu Suzhou Bo Wu Guan) in $2007^{4}$. Based on the authors' experience of working with Pei and his team, this book provides a more detailed documentation of the project's construction. Unlike the guidebook published by the museum, $\mathrm{Xu}$ and Ni's book shows their great respect of the world-class master architect. Although the book is not critical, it include information on Pei's own reflections about the museum and decisions made during the construction. Both books offer a wealth of photographs of the museum.

A documentary film about the new Suzhou Museum, released in 2010 and directed by Eugene Shirley. I.M. Pei: Building China Modern, presents Pei's ambitious goal of proposing a

3 Xin Zhang and Suzhou bo wu guan, Suzhou Museum (Beijing; London: Great Wall Publishers ; In collaboration with London Editions, 2007).

4 Ning Xu, Fumin Gao and Xiaoying Ni, Bei Yuming Yu Suzhou Bo Wu Guan = I.M. Pei. and Suzhou Museum (Suzhou: Gu Wu xuan chu ban she, 2007). 
new Chinese modern style in his designs of the new Suzhou Museum ${ }^{5}$. It also documents Pei's other projects and his friends' descriptions of the Suzhou Museum. The documentary emphasizes the difficulties and conflicting emotions Pei had during the design process, which are crucial for the thesis discussion. Another documentary film about his very last project the Museum of Islamic Art, was released two years later ${ }^{6}$. The project was designed in the same period as the Suzhou Museum. Although the film does not discuss the Suzhou Museum at length, it introduces another museum project of Pei's and provides several inspiring case studies of Pei's designs for other cultural buildings.

After the museum opened, there was an increasing interest in the cultural identity of the Suzhou Museum among scholars from both the east and the west. Paula Deitz, a cultural critic and garden specialist who pays close attention to Pei's designs, argues in her article, "Stone, Scrolls and Scholars," that Pei reflected the traditional form of Suzhou architecture in his modern design. She briefly describes the project's development and analyzes several key details from a Chinese cultural perspective. She concludes that the museum merged seamlessly with the old city $^{7}$. Like Deitz, Robert Ivy, now the Executive Vice President/ Chief Executive Officer at the

\footnotetext{
5 I. M. Pei: Building China Modern, directed by Eugene B. Shirley et al. (S.L.: PACEM Distribution International, LLC ;Oley, PA, 2010)

6 Learning from Light the Vision of I.M. Pei, directed by Landin, Bo., Van Wagenen, Sterling,, Landin, Marianne., Van Wagoner, Mark., Slickrock Films., Qatar Museums Authority.,Films Transit International Inc., ([Montreal, Quebec]: Films Transit International Inc., 2012)

7 Paula Deitz, "Stones, Scrolls and Scholars: Museum, Suzhou, China," Architectural Review 222, no. 1328 (10, 2007), 64-73.
} 
American Institute of Architects, argues that the Suzhou Museum succeeded by respecting its sensitive historical site and presenting an inspiring architectural model to new architects in China $^{8}$. These authors represent the majority of western scholars who emphasize Pei's Chinese identity and believe his design for Suzhou Museum was successfully Chinese.

The discussion among Chinese scholars is more intense. They often compare the new museum with ancient gardens in order to argue for the continuity or dis-continuity between them. Several Chinese scholars share the opinion of western scholars like Deitz and Ivy. They view the museum as a new cultural landmark designed by the grand master, who returned to his hometown and articulated a new Suzhou style for the city. Xiaoxia Fu in her article, "Application of Chinese Traditional Cultural Symbol to Suzhou Museum Design," compares the new museum with the old gardens from different perspectives, including the landscape planning, the color and the inner spirit. She argues that the Suzhou Museum successfully responded to its ancient neighbors. She believes the Suzhou Museum fits in the historical context harmoniously and creates a meaningful modern style with traditional cultural features ${ }^{9}$. Jun Zhang develops this argument further and describes the Suzhou Museum as an example of a Neo-vernacular, modern Chinese architecture. He points out that the landscape design of the Suzhou Museum intentionally adapts the gardening methods of ancient structures and reflects the beauty and

\footnotetext{
8 Robert Adams Ivy, "I.M. Pei Returns to His Family's Hometown in China and Designs the Suzhou Museum for a Sensitive, Historic Site," Architectural Record 195, no. 5 (05, 2007a), 186.

9 Xiaoxia Fu, "Application of Chinese Traditional Cultural Symbol to Suzhou Museum Design," Hundred Schools in Arts, no. S1 (2010), 93-94+150.
} 
elegance of Suzhou ${ }^{10}$.

However, another group of scholars believe that the Suzhou Museum failed to represent its Chinese identity in architectural form. Trevor Boddy, one of the few western scholars who criticizes the Suzhou Museum, argues that the Suzhou Museum is a clumsy expression of vernacular architectural culture ${ }^{11}$. The article, "The Analysis and Think on the New Suzhou Museum," written by Bing Luo, analyzes a number of "Chinese" elements of the Suzhou Museum and argues that those elements are merely superficial decorative icons, which cannot strongly remind visitors of the ancient gardens. Luo also criticizes the central design idea of the Suzhou Museum, "Zhong Er Xin, Su Er Xin," which could be translated as "traditional yet new" or "new Suzhou style," by pointing out the design result is a cold-hearted mixture of Pei's geometry and Chinese elements ${ }^{12}$. Her argument is supported by Yugan Dong in his "Prophesy and Allegory: Ieoh Ming Pei's Modern Chinese Architecture”. Dong argues that the idea of combining traditional Chinese style and modern style together to create a "traditional yet new" style is problematic. His article discusses the poetic origin of ancient Suzhou gardens' asymmetrical character and argues that Pei's design for Suzhou Museum is awkward. Besides the critical arguments about the Suzhou Museum's cultural identity, there are negative analyses

10 Jun Zhang, "Discussion on the Tendency of Neo-Vernacularism in Landscape Design Combined with the Courtyard Design in New Suzhou Museum," Huazhong Architecture, no. 01 (2008), 124-128.

11 Trevor Boddy, "IM PE1," Architectural Review 232, no. 1387 (09, 2012), 102-103.

12 Bing Luo, "The Analysis and Think on the New Suzhou Museum," Arts Exploration, no. 03 (2007), 123-125. 
of the museum site and planning as well.

My thesis analyzes the arguments of these scholars and reframes the Suzhou Museum as a self-portrait of its architect. Although the cultural implication of the museum's design has been discussed in many books and articles, the deeper relationship between Pei and his "youngest daughter,"13 the Suzhou Museum, has not been fully considered. Pei's nostalgia as well as his experiences in both his design career and personal life played a crucial role in his designs for the new Suzhou Museum. I will consider Pei's memories and his experiences in relation to his design method and the museum's resulting forms and spatial experience. Additionally, my thesis analyzes various project details that can be traced back to Pei's earlier designs. The thesis situates the Suzhou Museum within Pei's career and the larger context of contemporary architectural trends in China. My thesis utilizes primary sources and scholars' publications in both English and Chinese to analyze I.M. Pei's life experiences, his design method, and the select details of the Suzhou Museum in order to argue that the Suzhou Museum project was a distinctive biographical representation of Pei himself.

13 Pei called the Suzhou Museum his "Youngest Daughter." See Shirley et al., I. M. Pei: Building China Modern 


\section{Chapter 1 I.M. Pei's Return to Suzhou}

The Pei family had lived for more than six hundred years dwelling history in the city of Suzhou. According to Michael Cannell, "the first Pei arrived in Suzhou during the middle of the Ming Dynasty (1368-1644) to practice medicine and sell curative herbs." ${ }^{14}$ By the eighteenth century, the Pei family had already developed into an important landlord household. I.M. Pei's father, Tsuyee Pei was a prominent banker in modern pre-Communist China, one of the founders of the Bank of China. In the spring of 1917, I.M. Pei was born into this Chinese upper class family in Guangzhou. The same year, his granduncle, Runsheng Pei bought the Lion Grove Garden in Suzhou, which is particularly famous for its landscape of craggy rockeries. (Figure 3) Like most of the famous ancient Suzhou gardens, the Lion Grove Garden is now opened to the public. It was in this rockery garden that young I.M. Pei developed his knowledge of Suzhou architecture. Moreover, Pei's new Suzhou Museum is located within a 5-minute walking distance to this old family garden (Appendix A).

Pei's father used to be the manager of the Bank of China's Canton branch, until the Chinese civil war interrupted his career. Pei's family moved to Shanghai after things stabilized and his father rose to govern the country's key bank. Always moving with his father, I.M. Pei knew very little about his family history in Suzhou before the age of ten. During his early days in Shanghai, I.M. Pei was occasionally brought to Suzhou by his grandfather, Litai Pei, who wanted to teach

14 Cannell, I.M. Pei : Mandarin of Modernism, 33 
the young Pei more about Chinese culture. Litai Pei was a traditional Confucius Chinese gentleman, who refused to wear western suits and required the family to obey traditional Chinese manners. Litai loved his grandson very much. He often brought I.M. Pei to play in the Lion Grove Garden, which was owned by Pei's granduncle. In China, Laojia (which means family hometown) "goes a long way towards defining an individual." 15 Family hometown is viewed as a cultural aspect of the deep inner nature of an individual which should never be forgotten. Although Pei only spent a few months in Suzhou, he kept a wonderful memory of the city. According to Sandi Pei, his father Ieoh Ming often talked with him about how he played hide and seek in the rockery with siblings in the family garden. ${ }^{16}$

Pei's talent in architecture design was discovered in Shanghai. When Pei saw the construction of the high-rise Park Hotel at the Shanghai Bund, he was obsessed by the structure (Figure 4). "I was fascinated by the idea of a building of that height... It was as exciting to me then as the idea of going to the moon is to youngsters today. I decided that was what I wanted to do,"17 said I.M. Pei. Although Pei's father was not pleased by his son's interest, Pei chose to study architecture at the University of Pennsylvania, which was one of the most popular design schools among Chinese student in early twentieth century.

In August 1935, the seventeen-year-old I.M. Pei left China and started his architectural

\footnotetext{
15 Ibid.

${ }^{16}$ Lizhong (Sandi) Pei. Interviewed by Huang Chenying. Personal interview. New York City, October 24, 2013.

${ }^{17}$ Cannell, I.M. Pei : Mandarin of Modernism, 59
} 
study in the US. However, the classic curriculum presided over by George Simpson Koyle and Paul Cret made Pei feel bored and disappointed. The students at the University of Pennsylvania were expected to follow the Ecole des Beaux-Art training system; they focused on producing classical hand-drawing plans and decorative rendering graphics. But Pei's strength lay in mathematics, and he never wanted to be an artist. Two weeks later, Pei transferred to the Massachusetts Institute of Technology to study engineering instead of architecture under the influence of his friends there. Although Pei was more interested in engineering, his talent in architectural design was discovered by William Emerson, the dean of the school of architecture, who successfully persuaded him to return to architectural study. Pei then was returned to the Beaux-Arts training system, but he was not satisfied. A product of a traditional Chinese family, Pei did not find his love of classical decorations, instead, he was attracted by clear geometry and the expression of volumes. Inspired by the 1932 International Style exhibition in the Museum of Modern Art curated by Philip Johnson and Henry Russell Hitchcock, Pei started his own research in the library on different inspirations, especially on Le Corbusier. In the winter of 1935, Le Corbusier was invited to spend two days at MIT. Pei described it as "the two most important days in my professional life." 18

Originally, Pei planned to returning to China in 1940 after he graduated from MIT, but his father dissuaded him. By that time, the whole country was deeply involved in the Second

\footnotetext{
${ }^{18}$ Ibid.
} 
Sino-Japanese War. Therefore, Pei did not return to China until 1974 when he went to Beijing for the Fragrant Hill Hotel project. When he left MIT, Pei then met his wife Eileen Loo, who introduced him to the Harvard Graduate School of Design, where a new style was advocated and taught. Two important figures at Harvard were Walter Gropius and Marcel Breuer, who trained an extraordinary group of architectural talents, including Paul Rudolph, Henry Cobb, Harry Seidler, Philip Johnson and of course I.M. Pei (Figure 5).

Pei learned a lot from Gropius, but did not always agree with him. He raised the question of International Style versus vernacular culture to Gropius while he was working on his graduate thesis. Pei was thinking about the architectural imperialism of the International Style and the potential problematic replacement of Chinese indigenous style with western glass and steel. "What about climate? What about history? What about tradition?" he said. "Very interesting... You have to prove it to me"19 Gropius answered and asked Pei to do an individual project on this question. Pei came back to Gropius with his graduate thesis design: a two-story Shanghai art museum (Figure 6). With no decorative Chinese icons, Pei used a human-scaled design to present Chinese culture and its relationship to Chinese arts. The design tried to balance the modern western architectural style with private Chinese gardens, but the result was still described as modern "International Style." Different from other grand public museums, this small-scaled private museum caught Breuer and Gropius's eyes. Gropius said Pei's thesis was

\footnotetext{
19 Ibid.
} 
"the finest piece of student work I've ever seen," and believed it showed "an able designer can still well hold on to basic traditional features without sacrificing a progressing conception of design. ${ }^{20,}$

After graduating from Harvard, Pei's career as an architect started. In 1955, Pei with Eason Leonard and Henry Cobb founded the firm I.M. Pei \& Associates, in which Pei accomplished most of his compelling projects such as the East Building of the National Gallery of Art in Washington D.C., the Grand Louvre in Paris, and the Bank of China Tower in Hong Kong. The firm changed its name to "I.M. Pei \& Partners" in 1966 then to "Pei Cobb Freed \& Partners" in 1989. The partnership received the Architectural Firm Award of the American Institute of Architects in 1968. Pei retired from full-time practice of Pei Cobb Freed \& Partners in 1990 and began to dedicate himself to cultural projects allowing for more creativity. In 1992, the Pei Partnership Architects was founded in New York City by Chien Chung (Didi) Pei and Li Chung (Sandi) Pei, sons of Ieoh Ming. The Suzhou Museum discussed in the thesis was designed by Pei in cooperation with Pei Partnership Architects.

\section{- The Chinese Root}

In addition to his design talents, what makes Pei special is his dual-cultural background, which is a popular topic among not only his friends and co-workers but also architectural

\footnotetext{
${ }^{20}$ Ibid.
} 
scholars.

Most western scholars and architects willingly emphasize Pei's Chinese personality. Pei's Chinese life style is also discussed among western architects. Cannell in the chapter "China Again" provides readers a collection of views towards Pei's dual-cultural identity: Henry Cobb once called Pei a "cultural cross-dresser"; Martin Filler said "he has tapped into the Oriental stereotype of cleanliness, refinement and rationality"; Philip Johnson pointed out "he can talk about his ancestors and the stone gardens of Suzhou in the most aristocratic way. I would too if I were a Chinese gentleman. Why not? We all use what we can." ${ }^{21}$ One of Pei's daughters Liane said: "In certain ways he considers himself an American. He is after all, the classic American success story... But he remains very Chinese in the way he thinks about his personal life and his family.",22

Pei was also willing to emphasize his Chinese side. He once told his friend William Walton that, "I'm very westernized but it's far from complete... between me and Westerners there is a curtain, not as thick as a Bamboo Curtain, but a thin curtain that sets us off from one another in the final analysis..." And when Walton replied to Pei that he never thought of him as a foreigner, Pei responded: “Oh, but I'm much more Chinese than you think. I don't show it to you, I guess. I don't know whether that's on purpose." ${ }^{23}$ In a conversation with Gero von Boehm, Pei again

\footnotetext{
${ }^{21}$ See Ibid.

${ }^{22}$ Ibid.

${ }^{23}$ Ibid.
} 
described his Chinese background as "very traditional":

"I was brought up in a typical Chinese family living in Shanghai. It was actually not at all cosmopolitan. It was a very traditional family. Therefore, the Chinese values were very much ingrained in me when I was a young man. In fact my grandfather was so insistent that I learn more about the so-called Chinese values that exactly this was the reason why he invited me to stay with him in Suzhou. It sort of made me feel tied to the long line of ancestors. In other words, the Confucian values were pretty much my upbringing. Of course, I had the other side in my early life when I lived in Hong Kong with my family because my father was a banker there. I was able to see a little bit of the West. The upbringing was absolutely Chinese."24

Although Pei's architectural education was absolutely modern western, he believed the memories of Suzhou had influenced his design: "I was not aware that I learned anything from my experiences in Suzhou until very later. When I think about it in retrospect I must say that, yes, it did have an influence on my work. It made me aware of the complementarity of man and nature, not of nature alone. Somehow, the hand of man joined with nature becomes the essence of creativity. The gardens of Suzhou taught me that lesson. ${ }^{25}$ He even claimed himself as a Suzhou native after he signed the project proposal for Suzhou Museum: "Seventy years ago, I

24 I. M. Pei and Gero von Boehm, Conversations with I. M. Pei : Light is the Key (Munich ;New York: Prestel, 2000), 23.

${ }^{25}$ Ibid. 
lived in Suzhou for three months. After that, when people in the US asked me 'where are you from?' I always answered 'Suzhou'.,26

But when he realized the difficulty of the project, of re-discovering his hometown, his confidence of Suzhou cultural identity wavered. The architect keeps a number of treasured memories of Suzhou. They faded away or were romanticized during the time. Thus, when Pei came back to Suzhou after seventy years, he had a complicated feeling for the city. He felt he knew the city, but not enough for his design. He talked in Suzhou dialect with local people, but the most familiar language for him was always English. Unlike the young ambitious Pei, who was presenting his dual-cultural thesis design, the senior architect found it was very difficult to balance tradition with modernity, East with West. "I'm a foreigner here," the architect said ${ }^{27}$.

\section{- The Project Background}

The new museum in Suzhou is adjacent to the old museum structure, Prince Zhong's Mansion, which is a historic site in the city. The preparation committee for Jiangsu province Museum was set up in 1954, five years after the rebirth of the country. The Prince Zhong's Mansion in the city of Suzhou was chose to be adapted as the museum site. The Jiangsu province museum was opened on October 1, 1957. However, the old mansion was too limited in its spacefor the expansive collections. Two years after the opening, the government of the Jiangsu

26 Xu, Gao and Ni, Bei Yuming Yu Suzhou Bo Wu Guan =I.M. Pei. and Suzhou Museum, 29

27 Shirley et al., I. M. Pei: Building China Modern 
province decided to relocate the museum to the provintial capital of Nanjing and to integrate it in a much larger ancient temple complex. The museum in Prince Zhong's Mansion was reopened in the New Year of 1960, renamed as Suzhou Museum, a local museum (Figure 7, 8). The entire museum site comprised more than ten thousand square meters. Even though the museum was limited by the extant ancient structures, the Suzhou Museum still possessed no less than two thousand square meters of exhibition space. In 1961, Prince Zhong's Mansion was nominated as national heritage of China and was identified as the best-preserved historic site of Taiping Rebellion royal architecture. With the development of Suzhou Museum and of renovation project of Prince Zhong's Mansion, more and more problems were exposed to museum curators, historians and preservationists. On one hand, the curators required more exhibition space and climate control in the old mansion. On the other hand, historians wanted to preserve the ancient structure from museum exhibition installations. It was very difficult to balance the preservation of the historic site with the light and climate requirements of the museum.

During the conference of Suzhou Municipal People's Congress and Suzhou CPPCC (Chinese People's Political Consultative Conference) in 1998, several members and representatives proposed building a new Suzhou Museum. This proposal caught the attention of the Suzhou governors. They soon put the new museum project on the agenda.

Suzhou governors shared the idea that "the new Suzhou Museum should be built with up-to-date technology and should also represent local traditional spirit. It is an expectation of this 
2500 years old city. It must be designed perfectly."28 To share a historical connection with the old city, the Suzhou government made an adventurous proposal for the new museum site.

The site of the Suzhou museum is special and crucial to both the city and the project. The new Suzhou Museum is located in the historic inner city of Suzhou on the Pingjiang Road (Figure 9), adjacent to the biggest and also the most famous garden in the city, Zhuozheng Garden and the old museum structure, Prince Zhong's Mansion. Both are "Major Historical and Cultural Sites Protected at the National Level." ${ }^{29}$ Zhuozheng Garden is also an UNESCO-protected heritage site. (Appendix B) The Suzhou Folk Custom Museum, which used to be Pei's family's ancestral hall, and the Lion Grove Garden are locate to the south of the new museum site. (Appendix A) Pei viewed the site as a place surrounded by cultural heritage: "It's the 'Holy Land' in my heart.",30

Early in 1994, the mayor of Suzhou first visited Pei in New York to propose that Pei designing a new building for the Suzhou Museum. "Linked to the commercial waterway called the Grand Canal, Suzhou is encircled by a moat that defines the old city and feeds a labyrinth of side canals lined with one- and two-stores white-washed houses with grey tiled roofs and crossed by picturesque bridges. ${ }^{31}$ The old Suzhou museum gate was facing an ancient waterway. On an

$28 \mathrm{Xu}$, Gao and Ni, Bei Yuming Yu Suzhou Bo Wu Guan = I.M. Pei. and Suzhou Museum, 13

${ }^{29}$ A "Major Historical and Cultural Sites Protected at the National Level" is a historic site listed as of significant historical, artistic or scientific value by the State Administration of Cultural Heritage, which is the cultural relics administrative department of the State Council of China.

$30 \mathrm{Xu}$, Gao and Ni, Bei Yuming Yu Suzhou Bo Wu Guan =I.M. Pei. and Suzhou Museum, 26

31 Deitz, Stones, Scrolls and Scholars: Museum, Suzhou, China, 64-73 
earlier visit, Pei had observed that with no modern waste control, the water was unhealthily polluted. Thus, he declined the proposal and asked the government to improve the water condition of the old city canals.

Eight years later, in 2001, the mayor of Suzhou came back to Pei with a brave proposal to building a modern museum deep in the historic district at the intersection of two water canals in the northeastern of the old city. The mayor brought Ping Tan and Kun Qu to Pei's home and showed Pei how the city had developed in recent years ${ }^{32}$. This time, the water problem had been solved and Pei became excited about the site. "The location could not be more exciting. It's a very special site, surrounded by a wonderful garden." 33 According to Pei, "I was born in this country and educated in this country. So when they asked me to build a museum for Suzhou, I found I cannot resist." 34 The grand master finally decided to return to his far-away hometown.

Although the Suzhou citizens held a more positive view of the site chosen for the new museum, some scholars still think the decision was inappropriate. Yuhui Zhu from Tongji University points out that the new museum site blocks the southwest wall of the Zhuozheng and interrupts the continuity and the integrity of the ancient structures. Moreover, the museum creates a dead end and a wasted walkway at Zhuozheng Garden's southwest corner, which never

\footnotetext{
32 Both of PingTan and KunQu are traditional Chinese operas that originated from Suzhou. They are still locally popular among Suzhou area today.

33 I. M. Pei and Robert Adams Ivy, "At the Twilight of His Career, I.M. Pei shows Few Signs of Slowing Down," Architectural Record 192, no. 6 (06, 2004), 204.

34 Shirley et al., I. M. Pei: Building China Modern
} 
appeared in ancient garden designs. ${ }^{35}$ But Pei was attracted by this controversial site choice. The site not only provided a serious challenge, but also an exciting opportunity.

After retirement, Pei preferred commissions outside the United States, largely because of his experience designing the addition of the Louvre in Paris with its famed glass pyramid: "That project taught me that to know a country you have to work there on a project of consequence... so after that project I told myself, 'Let's learn about the world." ${ }^{\prime 36}$ Pei once said: "To create a work of architecture that looks exciting and different is not the challenge for me anymore. The challenge is for me to learn something about what I'm doing."37 Pei liked challenging site and the opportunity to learn from different building contexts, different cultures. From the East Wing of the National Gallery of Art to the pyramid of Louvre, he carefully selected those controversial projects. During an interview about the Museum of Islamic Art project, Pei expressed his pride of having projects all over the world. ${ }^{38}$ By accepting the commision for the Suzhou Museum, he saw a chance to inspire China, which was in the midst of a construction boom, to consider its own rich culture history, to be "neither a weak imitator of the Western Modernism nor a slave to the ancient traditions." ${ }^{39}$ Most importantly, Pei found a chance to reconstruct his Chinese

35 See Yuhui Zhu, "A Typical Misinterpretation of Architectural Heritage-The Pity of Suzhou Museum," Proceedings of International Conference on Chinese Architectural History IV (2003), 582-583. 36 David Barboza, "I. M. Pei in China, Revisiting Roots," New York Times (10/09, 2006), 1.

37 Pei and Ivy, At the Twilight of His Career, I.M. Pei shows Few Signs of Slowing Down, 204

38 See Landin, Bo., Van Wagenen, Sterling,, Landin, Marianne., Van Wagoner, Mark., Slickrock Films., Qatar Museums Authority.,Films Transit International Inc., Learning from Light the Vision of I.M. Pei

39 Shirley et al., I. M. Pei: Building China Modern 
identity, which he had emphasized as a central aspect $f$ his identity: "I thought the project would touch on my relationship with my past, my ancestors, my old home, ${ }^{, 40}$. After establishing his career and fame in the west, Pei finally has the opportunity to grapple with his memories of Suzhou.

In order to show his respect for the historic site, Pei made a number of physical connections between his museum and ancient structures. The body of water at the Suzhou Museum connected the new landscape with the Zhuozheng Garden. The water flowing through the shared wall at the southwest corner of the ancient garden into the new pond of Suzhou Museum provides an organic link with the ancient garden. The museum exit stands in the Prince Zhong's Mansion, so it leads visitors to discover the ancient building after their visit through the modern museum (Appendix C, D). He even required the Suzhou government to close Pingjiang Road (where the entrances to the museum and the garden were located) to vehicles to make it accessible only by pedestrians. Thus, visitors have a better sense of the entire historical cultural area without passing cars.

The choice and general planning of the museum site represents Pei's goal of fitting his museum into a historical context. He wanted to embrace his past and wished the historical city could accept his new design, accept his return. That is to say, the museum is like Pei himself, a Chinese American who came back home after a long time, who was eager to restore the cultural

40 Ivy, I.M. Pei Returns to His Family's Hometown in China and Designs the Suzhou Museum for a Sensitive, Historic Site, 186 
connection with his hometown. The design of the Suzhou Museum was Pei's self-construction as a Suzhou person. The connections he made between ancient structures and the new museum are not only physical but also sensorial: Pei believed his design method was essentially related to traditional Suzhou architecture. 


\section{Chapter 2 The Design Method}

\section{- Catching the Essence}

Pei has his own method of designing cultural projects in his active retirement, which is the "Key Feature". In order to design a modern building with traditional vernacular cultural roots, Pei will take a trip to local historical sites aiming at finding the "Key Feature" of a place or the "essence of a particular kind of architecture". ${ }^{41}$ He used the same method on the project of Museum of Islamic Art, where he found the key characters of the Islamic architecture are pure geometry and their relationship with light. 'It's the question of finding the spirit of the place, the history of the place". ${ }^{2}$ Pei said. It is a real challenge to find the essence of Suzhou architecture, the tone of Suzhou. The studies of Suzhou gardens are rich and complicated. Scholars spend their whole lifetime studying gardens. One can name a number of superficial features as well as cultural essences around the ancient garden art of Suzhou. But instead of trying to adapt all traditional elements onto a modern building, Pei only wanted to translate the "key essence" he found into a modern expression.

The search for an essence of Suzhou architecture could not easily be undertaken by anyone, especially for this old man who was educated, worked, and lived seventy years of his life in the United States. Pei questioned himself: whether a modern art museum is the right thing for

\footnotetext{
${ }^{41}$ Lizhong (Sandi) Pei. Interviewed by Huang Chenying. Personal interview. New York City, October 24, 2013.

42 Shirley et al., I. M. Pei: Building China Modern
} 
Suzhou? Unlike many western scholars, who compared the water-born city Suzhou with Venice, Pei has his own idea: "There is no place like Suzhou. No, not Venice, not Amsterdam... Suzhou is a small-scaled city, a human-scaled city... and I think the museum should reflect this."43 $\mathrm{He}$ wished the new museum became a harmonious part of the old city. That is to say, he wanted the museum be designed very Suzhou.

In April 2002, Pei and two of his sons arrived in Suzhou. They carefully examined the city and the proposed location for the museum. "Though I once lived in Suzhou and have some knowledge of its history and artists, it was inadequate for my designing, "44 Pei said. He walked through the old city, tried to puzzle out his childhood memories. During the project meetings, Suzhou governors and local artists raised several suggestions, such as: Suzhou is a delicate historic city with limited-scale (Pei called it "human scale"). Ancient gardens in Suzhou are different from gardens in northern China, such as the Summer Palace in Beijing (YiHeYuan), a typical northern style garden with royal and extensive characters. Suzhou gardens hide pagodas and rockeries inside the landscape, and hide themselves inside the wall. The museum should follow the character of the city_ "small", delicate and hidden away. In a word, they wished the design of the new museum would match the spirit of Suzhou and fit into the city's landscape. ${ }^{45}$ They also came up with a slogan for the new museum design: "Zhong Er Xin, Su Er Xin", which

\footnotetext{
43 Ibid.

44 He Yan, "I.M. Pei and His "Lovely Youngest Daughter."," China Today 56, no. 11 (11, 2007), 44.

45 See Xu, Gao and Ni, Bei Yuming Yu Suzhou Bo Wu Guan =I.M. Pei. and Suzhou Museum, 26
} 
means "traditional yet new" or "new Suzhou style". During a design consultation, a committee of ten academicians from Beijing, Nanjing and Suzhou met with Pei and together made a plea for keeping the traditional white-washed plaster walls with Suzhou-style black (in reality a blue-grey) overlapping curved roof tiles. ${ }^{46}$ Pei also held meetings with Kaiji Zhang and Liangyong Wu, two of China's most prominent modern architects. ${ }^{47}$ After he returned to the US, Pei devoted himself to the study of the city's history and culture. He also requested that the museum curators send him information about the collections and future exhibitions.

Finally, Pei found the key character for his design: the profile of Suzhou. (See Figure 2) The dark gray tiled roofs and the white walls create the distinctive profile of the city. There is no high-rise building in the historic inner city of Suzhou. Every house shares the same dark gray roof tile structure and eave angles, which contribute to the city's delicate skyline. The color and the angle are two essential forms Pei caught in the city. As Pei wanted to create a connection between his design and ancient heritages, he carefully translated this profile into his geometry language and adopted it everywhere in his design. He tried to reflect the skyline view of the city with his design for the Suzhou Museum.

In order to make an ancient structure into modern style, Pei abandoned all the ancient eave decorations and structures and adopt them into a forty-five degree angled grey granite roof, which "permitted him to build up the walls volumetrically into the cubist forms he deems

46 See Deitz, Stones, Scrolls and Scholars: Museum, Suzhou, China, 64-73

47 Yan, I.M. Pei and His "Lovely Youngest Daughter.", 44 
intrinsic to modern architecture." ${ }^{48} \mathrm{He}$ also abstracted the traditional tiles to a flat diamond-shaped roof pattern. (Figure 10) The angle and the grey-white color tone were carried on every detail: the roofs, the gates, the windows, and even the stairs. (Figure 11, 12, 13) It is a rhythm that can be found floating both interior and exterior. According to Sandi Pei, his father wanted to use these two characters as the inter-media that connect the detail and the scale of the entire project. In other word, Pei wanted each part of the museum to be represented in the same language of geometry. ${ }^{49}$

Building the angled roof was a lesson Pei learnt from his Fragrant Hill Hotel project in Beijing. Pei's Fragrant Hill Hotel (Figure 14) was highly criticized for its no-roof façade, as if the traditional roof was the only key character of Chinese architecture. In fact, the "big roof" trend did play an important role in the development of modern Chinese architecture, even in the contemporary city planning. Modern buildings with decorative un-functional traditional-looking roof structures can be found in many cities. Moreover, it seems that the fastest way to practice a Chinese Urban Renewal project is to build a series of fake traditional-angled roofs for shops along historic streets. Although this phenomenon is criticized by a number of scholars and architects today, it is still popular in many places. By designing the Fragrant Hill Hotel, Pei attempted to build modern Chinese style in the 1980s. But it may take people more time to

48 Deitz, Stones, Scrolls and Scholars: Museum, Suzhou, China, 64-73

${ }^{49}$ Lizhong (Sandi) Pei. Interviewed by Huang Chenying. Personal interview. New York City, October 24, 2013. 
accept his attempt.

Thus, unlike the Fragrant Hill Hotel, Pei kept the roof in order to reflect his Suzhou profile. He neither abandoned the roof to build a modern box, nor stayed with the traditional tile structure to make a clumsy new copy. As discussed earlier, he adapted the traditional structure into his grammar. After Pei presented his initial scheme to the Suzhou governors, they were unhappy about what the architects did to the roof. They believed it was extremely wrong to abandon the traditional tile roof that characterized the Suzhou architecture. They told Pei: "You made a very big mistake. You should use the tile roof. This is a tradition in Suzhou. ${ }^{" 50}$ However, Pei rejected their proposal for the tile roof, not only because he realized the tile roof was too thin and too delicate for a modern museum, but also because the architect thought it could limit the design possibility. "I don't know how to do a [modern] building like that [with traditional tile roof]. The reason is because tile roof is so strong a personality, it actually makes it impossible for you to make form out of it, because the roof is absolutely too dominant." ${ }^{, 51}$ Instead of gray tile roofs, Pei preferred a form that would develop volumes. Thus he "let the walls climb onto the roof" 52 and replaced the old tile with diamond patterns. For Pei, to take the tile roof away is to remove of the old durance, which makes it possible to innovate. Sandi Pei believed his father created a modern architectural language out of the traditional form by simply pushing the roof

\footnotetext{
50 Shirley et al., I. M. Pei: Building China Modern

${ }^{51}$ Ibid.

52 Barboza, I. M. Pei in China, Revisiting Roots, 1
} 
back without going beyond the wall ${ }^{53}$, which means to design a roof with no complicated eave structures. In other word, Pei's team believed a building covered with dominant roof is still conventional, while a building without exceeded roof eave is modern. In fact one can hardly recognize the roof of Suzhou Museum. The roof has been blended into the geometrical form.

(Figure 15, 16, 17)

The final scheme is highly geometrical, like overlapped toy bricks. "He use the geometrical form as his basic element and repeated the theme throughout," said Jia Beisi, Associate Professor of architecture at the University of Hong Kong. "The design looks like a big building cut into smaller pieces." ${ }^{54}$

\section{- The Problematic Method}

Scholars hold opposite opinions towards the design of Suzhou Museum. Robert Ivy thinks the form of Suzhou Museum "sacrifices bold formalism for a kind of Postmodern deconstructivism (not an oxymoron in this case), in which underlying historic themes are broken into shards, rendering prevailing geometries into motifs that fit within the structures of the surrounding walled courtyard... the effect is crisp, articulated, and decidedly modern." ${ }^{, 55}$ Xiaolei

\footnotetext{
53 Lizhong (Sandi) Pei. Interviewed by Huang Chenying. Personal interview. New York City, October 24, 2013.

54 Xiaolei Jing, "Mixed Motives," Beijing Review 51, no. 30 (07/24, 2008), 24.

55 Ivy, I.M. Pei Returns to His Family's Hometown in China and Designs the Suzhou Museum for a Sensitive, Historic Site, 186
} 
Jing points out that "Suzhou Museum is a blend of ancient and modern, designed to both stand out and fit in and be creative yet functional." ${ }^{56}$ Harry Perlmutter believes the project reflected "Pei's turn away from pure statement of form in favor of culturally emblematic modes and motifs." ${ }^{57}$ Mrs. Keswick argues that "the great Mandarin has recreated the essence of what his family lost." ${ }^{, 58}$ The famous architectural historian Luo Zhewen thinks Pei's design is successful for getting the essence of traditional Chinese architecture and recreating it in a new way. Ruan Yisan from Tongji University even says the project should be written into the textbook for architecture students. ${ }^{59}$ To sum up, this group of scholars believes I.M. Pei’s design for Suzhou Museum achieved spiritual harmony with its contexts. Some of them even named it as a perfect new museum model of presenting traditional Chinese culture with new technology. ${ }^{60}$

However, other scholars argue that the museum form failed in expressing local spirit. Trevor Boddy argues that "the local vernacular is updated in steel, glass and concrete, but the result is elephantine, tired and cold-hearted, descriptors that apply also to Doha's 2008 Museum of Islamic Art." ${ }^{, 61}$ One of the Chinese scholars Luo Bing points out that even though the form of

\footnotetext{
56 Jing, Mixed Motives, 24

57 Harry Perlmutter, "Im Pei's Active Retirement," Art AsiaPacific, no. 53 (May, 2007), 71.

58 Tessa Keswick, "Cultural Renaissance in China's Venice.(Suzhou)," Literature Resource Center (Nov.11, 2006).

59 See Xu, Gao and Ni, Bei Yuming Yu Suzhou Bo Wu Guan =I.M. Pei. and Suzhou Museum

60 See Xin Zhang, Xuemei Lu and Xiaoting Xie, "Inheritance, Innovation and Integration--Construction and Exhibition Design of New Suzhou Museum," Art \& Design, no. 03 (2009), 27-30.

61 Boddy, IM PEl, 103.
} 
Suzhou Museum has features in common with the city's profile it cannot arouse the inner sympathy of Suzhou visitors. ${ }^{62}$

The Suzhou Museum is not a successful representation of Suzhou's essence. The museum design, essentially, is not Suzhou but a product of Pei's geometrical building philosophy. Some scholars believe Pei "departed from his signature style"63 on the Suzhou museum project; however, the form of the museum is very "Pei's style". During an interview about I.M. Pei and Suzhou museum, Charles Jencks thought Pei played a game in the museum form: "turn a wall into a rock, and then back into a wall and then to a roof." ${ }^{, 64}$ Pei abstracted the traditional form to create a geometrical rotation of cubes and triangles rising towards the sky. The drilled-back trapezoid façades provide spaces for sunlight, allow them to play on the volume, shape the edges and corners, and emphasis the geometric Suzhou profile. Squares and triangles interweave with each other in the game of gray and white, light and shadow. The same rotation can be found in his corresponding period project: the Museum of Islamic Art. (Figure 18) Some people thought Pei was obsessed by geometry. Pei did not deny this. ${ }^{65}$ Sandi also believes his father apprehends the language of geometry: geometry means endless creativities, which can generate forms. ${ }^{66}$ In

62 Luo, The Analysis and Think on the New Suzhou Museum, 123

63 Perlmutter, Im Pei's Active Retirement, 71-71

64 Shirley et al., I. M. Pei: Building China Modern

65 See Landin, Bo., Van Wagenen, Sterling,, Landin, Marianne., Van Wagoner, Mark., Slickrock Films., Qatar Museums Authority.,Films Transit International Inc., Learning from Light the Vision of I.M. Pei

66 Lizhong (Sandi) Pei. Interviewed by Huang Chenying. Personal interview. New York City, October $24,2013$. 
both of these late museum projects, Pei tried to create a clean new modern form, which is not about elements or any other superfluous things, but about the cultural essence. But he finally designed two similar geometrical forms for two radically different cultures.

Pei has an uncanny feeling for Suzhou ${ }^{67}$, which means Suzhou is familiar yet foreign for him. But Pei did not want to be a foreigner. Thus, he was eager to grab the chance to make a contribution to his hometown. There is an interesting nostalgia tradition in China called Luo Ye Gui Gen, which can be translated directly as "fallen leaves return to the tree's roots". That is to say, when a person is getting old he/ she will miss their hometown in a more nostalgic way. Therefore, designing the Suzhou Museum was a great opportunity for Pei to restore his memories and to re-identify his Suzhou identity. Pei not only did it for the city of Suzhou but also for himself, an old Chinese-American architect returned to his hometown and tried to discover his cultural roots. Pei wanted his project be accepted as a part of the city: "I don't know whether people think it is old China or new China. But I hope they think this is China."68 Building the new museum is a way to achieve his self-construction as a Suzhou person.

The following quote of Pei is inspiring and explains more about the project:

67 Sigmund Freud, David McLintock and Hugh Haughton, The Uncanny [Essays. English. Selections] (New York: Penguin Books, 2003), 124. In the book, Freud introduced the German word "unheimlich" as unhomely. Antony Vidler explain that "somebody who has uncanny experience is not quite zu Hause [at home] in the matter that he is not heimisch [homely], that the affair is foreign to him." See Anthony Vidler, The Architectural Uncanny : Essays in the Modern Unhomely (Cambridge, Mass.: MIT Press, 1992), 23.

68 Shirley et al., I. M. Pei: Building China Modern 
"Suzhou Museum-I think of it as part of me. And so, in many ways, this project is a biography for myself. And what little I remember of China... See, I left when I was very young, so what I remember of China is purely one of nostalgia... but it gave me a chance to somehow to make a physical expression of what I remember. ${ }^{.69}$

The Suzhou Museum project is a biography of Pei. With geometrical forms emphasized volume and limited adaptations of ornaments on façades, Pei's design for Suzhou museum reflected his educational background of modern architecture. The design method Pei used for Suzhou Museum was also problematic. It was too simple and abstract for Suzhou architecture. To abstract the essence of an ancient architecture is never an easy task. It is easy to confuse "abstract" with "abandon", as "to abstract" at some points means "to select the key point and abandon the others". "To abstract" requires one to dig out the essence of the source. It is about doing subtraction, about achieving the minimal recognition. Pei found the key character of the Suzhou architecture was its profile, which is superficial. Spiritual essences of Suzhou gardens, such as the poetic expression of ancient Suzhou scholars, were not taken seriously by Pei. Instead, he chose to imitate the external view of the city. The philosophy of Suzhou architectures and gardens is profound and rooted in the vernacular culture and cannot be abstracted as merely the single profile.

\footnotetext{
69 Ibid.
} 
For instance, Pei's design for the roof angle was simple and wishful. He thought the best way to hide the new museum into the landscape is to catch the roof angle. While, the traditional Suzhou tile roof was not built by merely following one single angle. The traditional roof was built up on multiple eave structures with complicated tile handicraft skills. Pei's roof abandoned almost every elements of the traditional Suzhou roof and only kept the angle. The traditional feelings and visual beauty were missing. Another feature Pei emphasized was the color: white wall and dark roof. Even though it is the same with the building context, the result is strange. The sharp geometrical edges and corners created a clear contrast of the two colors. The geometrical form is too strong and lacks the various beauties created by the eave structures.

The method came from Pei's architectural training under Gropius. As a student, Pei ran away from Beaux Art and embraced the International Style; sixty years later, he still pursued geometrical forms with no complicated traditional elements. The saying of "finding the essence" is suspicious. In fact, what Pei found for Suzhou Museum and the Museum of Islamic Art were not their cultural essences, but the abstract recognitions or the geometrical appearances. Therefore, the method led to a result of a modern design with a clumsy Suzhou profile, which is like a westerner wearing an ill-fitting Chinese robe.

The method reflected Pei's architectural education background of western modernism, and the form was developed from his geometrical language. Rather than expressing the spirit of 
Suzhou, the new Suzhou Museum presents Pei’s effort of negotiating with his hometown cultural identity. The general design of the museum became a self-portrait of its architect. 


\section{Chapter 3 Building as a Biography}

Pei believed his youngest daughter — the Suzhou Museum realized the dream. "I have not forgotten that Suzhou is not typical of China. You could not necessarily do this elsewhere. I am not trying to create a new vocabulary for young Chinese architects. But the people of Suzhou are not uncomfortable with it. It belongs to the Lake [Pingjiang] District." ${ }^{, 70}$ A single geometrical profile was far to present the museum's Suzhou characters. Pei designed more recognizable Suzhou elements for the project. However, the designs of detail, again, do not represent the essence of Suzhou but become an expression of Pei himself. Pei adapted a number of his earlier projects onto the Suzhou Museum, which made the project a mixture of Pei's former designs. Moreover, Pei created a hybrid rockery landscape based on his romanticized memory. That is to say, the Suzhou Museum project is a blend expression of I.M. Pei's biography. It is not only a transformation from the architect's experience but also a recreation of his romantic memory.

\section{- Pei's Signature}

I.M. Pei's initial goal was to build a modern museum with the cultural essence of Suzhou. However, scholars with formal knowledge of I.M. Pei's projects can name several hallmarks of Pei's earlier designs from the museum complex — his triangles, squares, and pyramid — "as well

70 Robery Ivy, "I.M. Pei, FAIA, on the Suzhou Museum," Architectural Record 195, no. 5 (05, 2007b), 190. 
as an expansive use of glass and light.."71 In fact, many key structures of Suzhou museum are not originally designed for Suzhou; they were borrowed from Pei's former projects.

The pagoda in the museum garden has an older twin sister in England-the Oare Tea Pavilion (Figure 19), which is one of Pei's smallest building projects. The Oare House is located in Wiltshire, England. Mr. and Mrs. Keswick commissioned I.M. Pei to design the pavilion in October 1999. The tea pavilion structure is a 43 feet by 43 feet octagon with a small square shape pagoda top. The museum is a product of the Miho Museum in Japan (Figure 20) and European teahouse tradition ${ }^{72}$. Mrs. Keswick visited the Miho Museum in Japan all the way from London during the ninetieth. After she returned home, she told her husband that the Miho Museum was one of the most spiritual and peaceful places she has ever been to and she wanted to have s a small version of it. Mr. Keswick's family had a long tea business connection with China and happened to know Pei's family.

Philip Jodidio the author of I.M. Pei: Complete Works describes Pei's tea pavilion as an Arcadian structure or a "folie" ${ }^{\text {,3 }}$. But due to the family business connection, Pei's Oare Tea Pavilion is more like a modern copy of the Chinoiserie teahouses from early seventeenth century. Paula Deitz also names this museum as an "updated 21-century Chinoiserie" ${ }^{\text {"74 }}$. After the Dutch East India Company introduced tea into Europe in the seventeenth century, the taste of

71 Barboza, I. M. Pei in China, Revisiting Roots, 1

72 Philip Jodidio and Janet Adams Strong, I.M. Pei : Complete Works (New York: Rizzoli, 2008), 367. 73 Ibid.

74 Paula Deitz, "IM Pei: A Life in Architecture," Architects' Journal 231, no. 4 (02/04, 2010), 43. 
Chinoiserie became a significant trend for architecture and decorative art in the western world. This fanciful style developed from the inaccurate views of Chinese art and architecture style and reflected the flashy taste of European royal families. (Figure 21)

While working on the Oare Pavilion, Pei must have noticed a possible prototype of the Chinoiserie Tea Pavilion in Suzhou, China-Ting (See Figure $3^{75}$ ). Ting is one of the major structures for ancient Suzhou Gardens. In Yuan Ye, Ting is described as a functional structure for ting, which is a different character with the same pronunciation, meaning "to stop or rest". A ting is a place where people can gather together and rest. It is a free-style structure, which had multiple models and should be designed according to the garden context. ${ }^{76}$ Pei designed a Ting shape pagoda in the Suzhou Museum garden. (Figure 22, 23) However, the steel-glass structure makes it a copy of his geometric Chinoiserie Tea Pavilion in England, which has little relationship with the traditional Chinese Ting structures. Sandi Pei believed his father designed this pagoda under the inspiration from Ting, however, with almost no specific features of the Suzhou architecture (or even the Chinese architecture), the pagoda is more like one of the imaginative geometric motifs of Pei.

There is another "borrowed design" in Suzhou Museum: the screen. The screen structure can be found everywhere interior under the roofs of museum buildings and of the pagoda (Figure 24, 25, 26). The Oare Tea Pavilion used the same structure. Many scholars misread this screen as

75 The center structure showed in the picture is Ting.

76 See Cheng Ji, Shikui Li and Jinpeng Liu, Yuan Ye (Beijing Shi: Zhonghua shu ju, 2011), 88. 
wooden structure in their articles. However, this wooden-look structure is made from aluminum. It is a strong metal structure with vivid wooden color and patterns, which is hard to tell from the real woods by eyes. This distinctive screen structure was actually an invention from Pei's Miho Museum project in Japan. Pei designed a wooden shoji style screen for Miho museum's lighting control. Although it looks pretty and elegant, the civil engineers denied this proposal: on one hand, the scales of the screen structure were so large that it was very difficult to make such kind of screens out of strong undivided woods; on the other hand, wooden screen structure were too delicate and hard-to-preserve. In other words, it was impossible to make a strong yet long-standing wooden screen as Pei wished. But Pei insisted on his original idea of using wood as the material. He believed that a metal structure would disrupt the peaceful and Zen atmosphere he wanted to create for the museum and refused to abandon wooden material. Plus, the metal screens would be too heavy for the glass roofs. Pei asked the engineers to find out a method of strengthen the wooden structure.

The Miho Museum engineers finally made an aluminum shoji screen with vivid fake wooden ornament on surface. The screen was light and strong with deceptive wooden look. The first time when the Japanese engineers showed their invention to Pei's group, Pei was extremely shocked. He was more than satisfied with the invention and used these new high-tech shoji screens under every roof of the Miho Museum. "We always like to see smart inventions for 
buildings," 77 said Sandi Pei. The result was inspiring: the screen controlled the sunlight effectively and even softened the dazzled light into a comfortable tone with its "wooden" texture. It helped the Miho Museum "demonstrate a fluid integration of structure and setting.," in love with this structure after the Miho Museum project.

Pei liked the lighting result of the shoji screen so much and could not help applying it on the Suzhou Museum project. He was famous for using sunlight, but museum projects always had strict sunlight control requirements. The soft light created by the roof "wooden" screen became a great new lighting source for museum buildings in Pei's eyes. The reason why he adapted a Japanese shoji screen on a Chinese museum was obvious: Pei thought this kind of screen could provide visitors an oriental peaceful feeling. However, a roof shoji screen is never a traditional Chinese feature. There was never this kind of lighting control roof structure in ancient Suzhou architecture.

The extensive use of roof shoji screens made the Suzhou Museum a sister copy of the Miho Museum. Plus, the triangle pyramid form also created a clear connection between these two projects. The only key difference of them is the wall material. The wall design of Miho museum is more like Pei's East Wing of National Gallery. But if we put the interior images of Pei's East Wing of National Gallery of Art, the Miho Museum and the Suzhou Museum all together in a

77 Lizhong (Sandi) Pei. Interviewed by Huang Chenying. Personal interview. New York City, October $24,2013$.

78 Jodidio and Strong, I.M. Pei : Complete Works, 274 
line, we can discover a clear "evolution" and transformations among them. Pei's signature style is clearly presented - geometry, roof sunlight and opened space, etc. Bing Luo also compared the Suzhou Museum with the Miho Museum in Japan. She argues that the two museum projects did not clearly present the differences between the two cultures. Too many similar details were used by the two museums, which definitely will confuse the visitors. ${ }^{79}$ Although Japanese garden art has an early influence from ancient Chinese garden art, the two kinds of gardens are still culturally different. But Pei's romanticized memory of Suzhou cannot help him differentiate the Suzhou culture from Japanese culture clearly. The uncanny feeling for the hometown confused him about East Asian arts.

The designs of the two key structures, Ting and shoji screen are borrowed from other projects, which have different cultural origins. They create an alien visual effect for the Suzhou Museum. The museum became a gallery of Pei's earlier designs. Rather than a museum originated with Suzhou, the museum was born in Pei's experiences. The Suzhou Museum is Pei's youngest daughter and each part of it could be traced back to her father's biography.

\section{- The New Suzhou Rockery}

The rockery corner of Suzhou Museum garden is also a representation of Pei's biography, especially his uncanny feeling for Suzhou. One of Pei's Suzhou memories is always mentioned

79 See Luo, The Analysis and Think on the New Suzhou Museum, 123-125 
by him during conversations or lectures. It is the story of ancient rockery making. The memory is about the Lion Grove Garden, or Pei translated the name directly as the Forest of Stone Lions:

"The Forest of Stone Lions was started by Taoist monk in the fourteenth century, and is famous for its rocks, which look rather like the works of Dubuffet. How such rock gardens are made is very interesting, and refer strongly to our perception of time and family relationships. The rock is usually a porous volcanic stone, which is chosen by a rock farmer for its sculptural possibilities. The rock farmer would carefully chisel the rock to open it up in a subtle way. Then the rock farmer would carefully select a spot near the edge of a lake or a river, with moving water, and would plant the rock there to erode in a natural way over a generation, or several generations. The farmer himself, or his son or grandson, would rather harvest the rock, and incorporate it into the composition of a garden. This sense of connection, of continuity, is an extremely telling aspect of Chinese culture - the father sows, and the son will reap." $\$ 80$

Pei repeated this story in many occasions: lecture in the Louvre, documentary videos, conversation with scholars, and dialogue on TV shows. The story of rock farmer is one of the most treasured Suzhou memories for Pei.

80 Pei and von Boehm, Conversations with I. M. Pei : Light is the Key, 18 
The northern walls of Suzhou Museum were adapted to the ancient Zhuozheng Garden. They make an interesting comparison and contrast with Pei's new structures. Although green twigs in the old garden provide a majestic background for the north end of the pool, which Deitz called a "borrowed landscape" ${ }^{\prime 1}$, they are still not enough to decorate the entire empty walls. Sandi Pei said they initially wanted to put some sculptures under the white wall, but they did not find a satisfactory art piece ${ }^{82}$. Pei chose a few twisted traditional-look rocks for the museum garden, like Tai Lake rocks in its neighbor, but he rejected the extensive use of traditional intricate rockeries into the new museum. Even though he often told his son about the memories of playing hide and seeks among the rocks in the Lion Grove Garden, Pei did not want to introduce this scene into the museum garden. The architect was stumped by this wall decoration problem until someone showed him a traditional Chinese ink painting of abstract overlapping mountain peaks by a Song Dynasty artist Mi Fu. (Figure 27)

Inspired by the painting, Pei came up with an idea for the empty wall: why not view the wall as a piece of paper and use rocks to create an ink painting on it? He dispatched Bing Lin, one of the young architects in his team, to Shandong Province to select aged granites and bring them back to Suzhou. With a copy of the Mi Fu's painting displayed in front of him, Pei directed

81 Deitz, Stones, Scrolls and Scholars: Museum, Suzhou, China; the "borrowed landscape" was one of the crucial ancient garden design methods. It means using sceneries out side the garden to decorate the inner landscape by planning special visual angles or effects.

82 Lizhong (Sandi) Pei. Interviewed by Huang Chenying. Personal interview. New York City, October 24, 2013. 
the crane worker to lift the 10-ton slices into position, to create an abstract silhouette rock painting against the garden wall. In order to imitate the vision of depth in the ink painting ${ }^{83}$, the rocks were orientated from dark to light towards the wall and were flame finished to imitate an ink-brush quality. Pei conducted the flaming and positioning works all by himself, even when he was in New York, where he continued "moving" rocks by emails. The result is distinctive: with the reflections in the pool, the rock painting creates a distinctive visual effect. (Figure 28, 29) Suzhou governors were satisfied, they even wanted to set artificial light sources to the trees in the Zhuozheng Garden to make a better background for the rocks. But Pei denied their proposal to show his respect to the ancient garden.

This "creative" rockery design catches scholars' attention. There is a hot debate around Pei's rock painting. Fu Xiaoxia thinks the stone image wall is a "crowning touch" of the museum, which perfectly combined the ancient spirits and modern ideas by using traditional cultural symbol. ${ }^{84}$ Paula Deitz holds the same opinion with Fu. She thinks the stone image wall is "emblematic of the architect's major design challenge". Deitz believes the fluent melody represented by the rock painting showed the spirit of Mi Fu's work and the spirit of Chinese art. "It is a triumph of landscape architecture," 85 She argues. There are more scholars believe "the

83 Traditional Chinese ink painting uses gray scale tones to represent the perspective depth, with darker color for the nearer objects while lighter color for the farther objects.

84 Fu, Application of Chinese Traditional Cultural Symbol to Suzhou Museum Design, 93-94+150

85 Deitz, Stones, Scrolls and Scholars: Museum, Suzhou, China, 64-73 
rockery presents the feeling of $\mathrm{Mi}$ Fu's Great Freehand Style ${ }^{86}$ landscape ink painting, especially during the typical drizzle days of southeast China",87.

Many scholars hold a different opinion towards the rockery painting. Pei once talked about his memory for Chinese gardens: "In a Chinese garden, you make a turn, and then you pause, you see something, and you turn again, and you see something different." ${ }^{, 88}$ But it is hard to "make a turn and see something different" in the new Suzhou Museum. Don from Peking University argued that the rockery painting, as the main scenery in the garden of Suzhou Museum, is too de-compacting to express any spirit. Compared with traditional ways of setting rocks, which could provide visitors rich aesthetic experiences, Pei's rockery design only has a single boring view. He also pointed out that one could even see the ugly water pipes or facilities hidden behind the stones. Thus, the rockery painting design should never be used as an aspect to prove that Pei "successfully" represented the essence of Suzhou garden. ${ }^{89} \mathrm{Zhu}$ from Tongji University criticizes Pei's rockery for interrupting the former connections to Zhuozheng Garden complex. It is a dead corner and blocks the beauty of Zhuozheng Garden. ${ }^{90}$ Bing Luo shared the

86 There are two major techniques of traditional Chinese ink painting: Fine-brush and Freehand style. The Freehand style includes two classes: the Great Freehand style, which is more abstract; and the Slight Freehand style, which is more delicate and representational.

87 Zhang, Lu and Xie, Inheritance, Innovation and Integration--Construction and Exhibition Design of New Suzhou Museum, 28

88 Perlmutter, Im Pei's Active Retirement, 71-71

89 Yugan Dong, "Prophesy and Allegory: Ieoh Ming Pei's Modern Chinese Architecture," Shi Dai Jian Zhu $=$ Time \& Architecture, no. 5 (09, 2007), 60-65.

90 Zhu, A Typical Misinterpretation of Architectural Heritage-The Pity of Suzhou Museum, 583 
same argument with Don. Luo believed that the rockery painting in Suzhou Museum gave visitors a Japanese art feeling rather than Chinese art. It provides visitors a dull feeling of solitude like watching the rain of falling cherry flowers-beautiful but fleeting. It is totally different from the rich experiences a Chinese garden can provide to its visitors. ${ }^{91}$ In fact, Pei's rockery design does share similar characters with the Japanese Rock Garden (the karesansui, or the "dry landscape" garden) (Figure 30), such as the setting of rocks and the Zen feeling, even though Sandi Pei believes the design has nothing to do with Japanese gardens ${ }^{92}$. The traditional Chinese arts of garden planning and ink painting have their own aesthetic system and expression methods. Copying an abstract ink painting cannot remind people of the ancient rockery scenery of the Suzhou garden or any traditional Suzhou landscape. The rockery landscape in the Suzhou Museum originated neither from the traditional Suzhou garden planning nor from Pei's earlier designs. It is a product of Pei's romanticized memory and understanding of Chinese gardens. It is Pei's imagination, which was used to negotiate with the vernacular culture.

91 Luo, The Analysis and Think on the New Suzhou Museum, 123-125

92 Lizhong (Sandi) Pei. Interviewed by Huang Chenying. Personal interview. New York City, October 24, 2013. 


\section{Conclusion}

This thesis originated from an interest in a biographical organization of architecture's history. I was intrigued by scholars' debates around the cultural identity of the new Suzhou Museum in relationship to Pei's dual-cultural background. After further research, I realized that a simple "Chinese or not" definition is not enough to explain the project and there is a compelling connection existing between Pei's biography and his Suzhou Museum. Although scholars always read Pei's buildings based on his experiences, very little has been written on the distinctive biographical identity of the Suzhou Museum. The Suzhou Museum, which is the only project I.M. Pei designed for his hometown, plus the architect's dual-cultural identity provide me a unique opportunity to analyze the architect's negotiation with his hometown cultural identity. Although Pei saw the Suzhou Museum project as an opportunity to reconstruct his Suzhou identity and tried very hard to express Suzhou spirits by his design, the museum represents little about the essence of the city and becomes a portrait of Pei himself. It is my hope that this thesis will provide a perspective from which to study the relationship of the architects and their cultural designs.

In the previous chapters, I have examined the complicated cross-cultural experiences Pei had and demonstrated that even Pei's relationship with his hometown Suzhou was not extremely strong and his educational background was all about western modern architecture, Pei shows a growing desire of looking back to his Chinese identity. The of project building a modern 
museum for his hometown on a critical historical site provided him a great opportunity to remember his Suzhou experience and reconstruct his cultural identity. The initial wish of Pei was to design a museum that can reflect the culture and spirit of the old city.

Pei used his distinctive cultural design method to achieve his goal. However, even though Pei claimed his method was to catch the essence of Suzhou architecture, the method was too simple and abstract. The profile of Suzhou, which is the essence Pei found by using his method, is a superficial feature of the city. The color and abstract roof angle are not enough to represent ancient Suzhou architectures. His method focuses on abstract geometrical expression and the possible development of volume and, after all, originates from his training on western modern architecture. The form he designed based on his method is a typical Pei's form and also represents his educational background.

The Suzhou Museum not only reflects Pei's biography by its form but also by its details. The garden pavilion and screen structures have prototypes in his earlier projects. They were originally designed for different cultural contexts: the garden pavilion developed from his Oare Tea Pavilion, which is a hybrid of Chinoiserie Ting and the Miho Museum; and the shoji screen was an invention from his Miho Museum Project. The adaptive reuses of former designs for the Suzhou Museum lead to an unclear visual cultural expression.

The rockery painting is another controversial cultural design in the Suzhou Museum. The new landscape was born from his treasured memory of Suzhou rockeries and his ambitious 
recreation of Mi Fu's ink painting. Rather than carrying on the spirits of ancient Suzhou gardens, it shows Pei's understanding and presentation of traditional Chinese landscape art.

Pei designed the museum based on his blurred childhood memories and later studies of Suzhou culture. The project represents the architect's romantic yet superficial understanding of ancient Suzhou architectures as well as his earlier projects and experiences. It shows the Suzhou profile in Pei's architecture language, but fails in catching the spirit of its ancient contexts. The project is a cross-cultural complex and a vivid portrait of Pei's sentimental emotions for his hometown. It is a biography of the architect.

The new Suzhou Museum opened on October 6, 2006, during the Mid-Autumn Festival. Every day since then, people from all over the world come to Suzhou to visit the museum not only for its thousands-year-old collections but also for the building designed by a world famous architect. The museum becomes not only a museum of Suzhou's cultural heritages, but also a museum of I.M. Pei as an architect. 
Appendix A: The site map of Suzhou

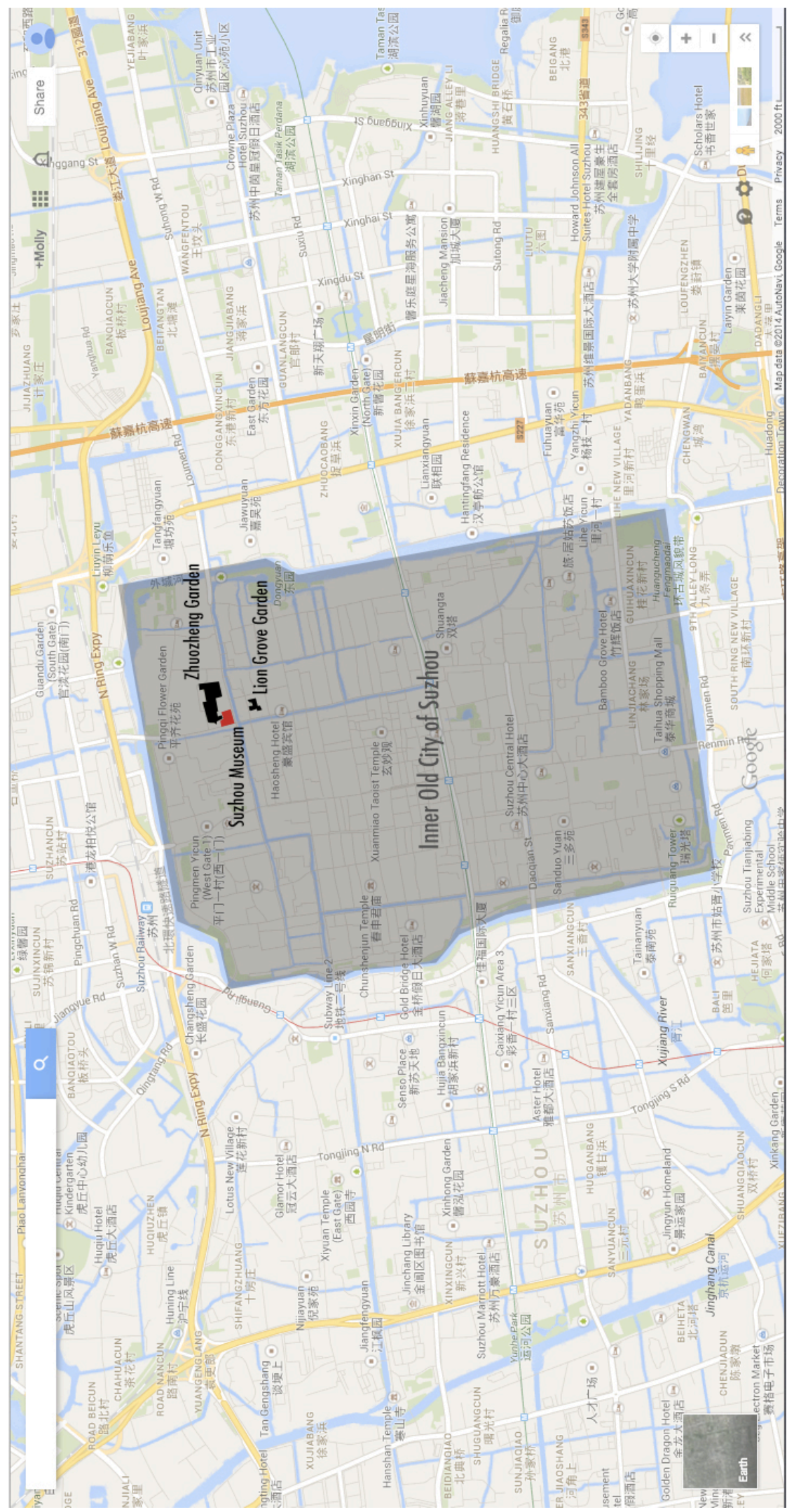


Appendix B: The site map of Suzhou Museum

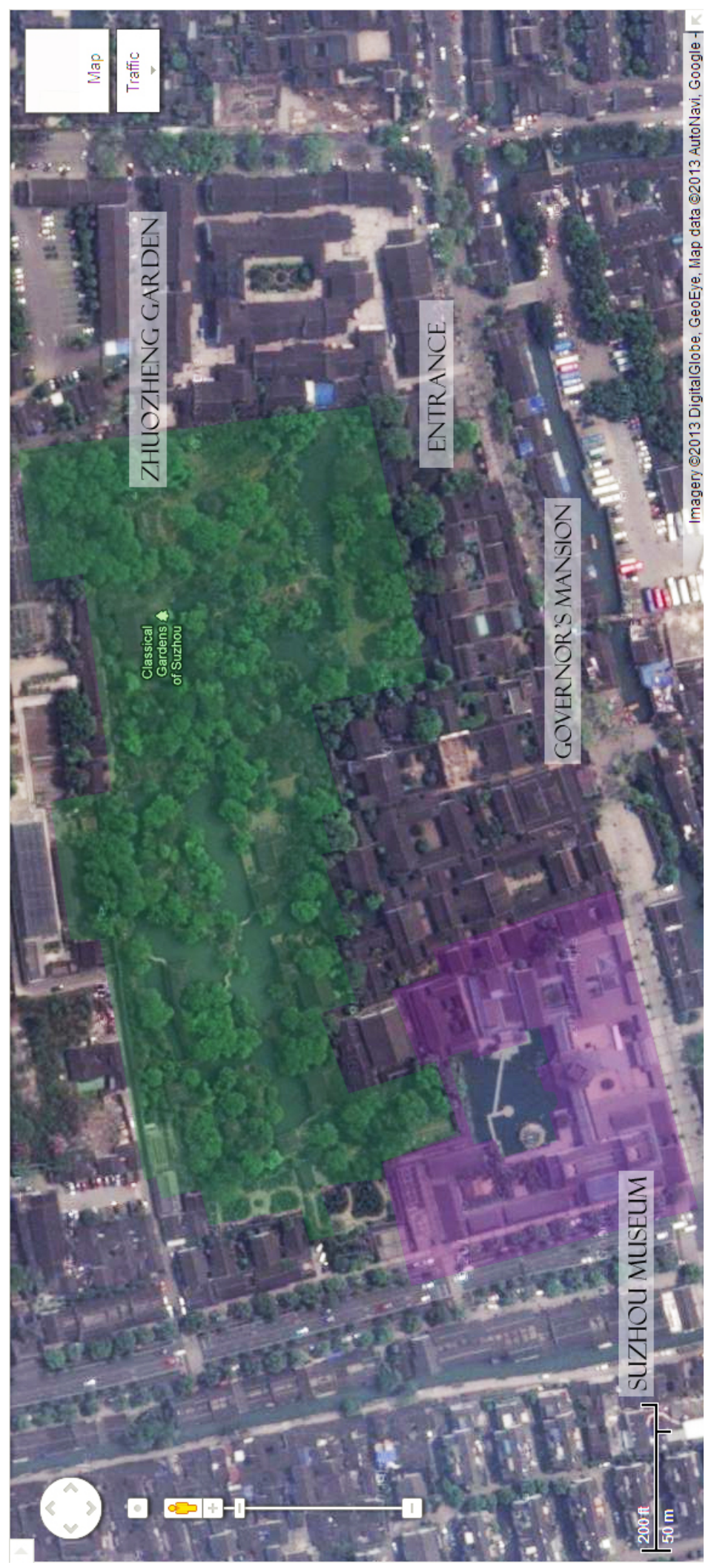


Appendix C: Axonometric CAD Drawing, Southeast



\section{Appendix D: Site Plan CAD Drawing}
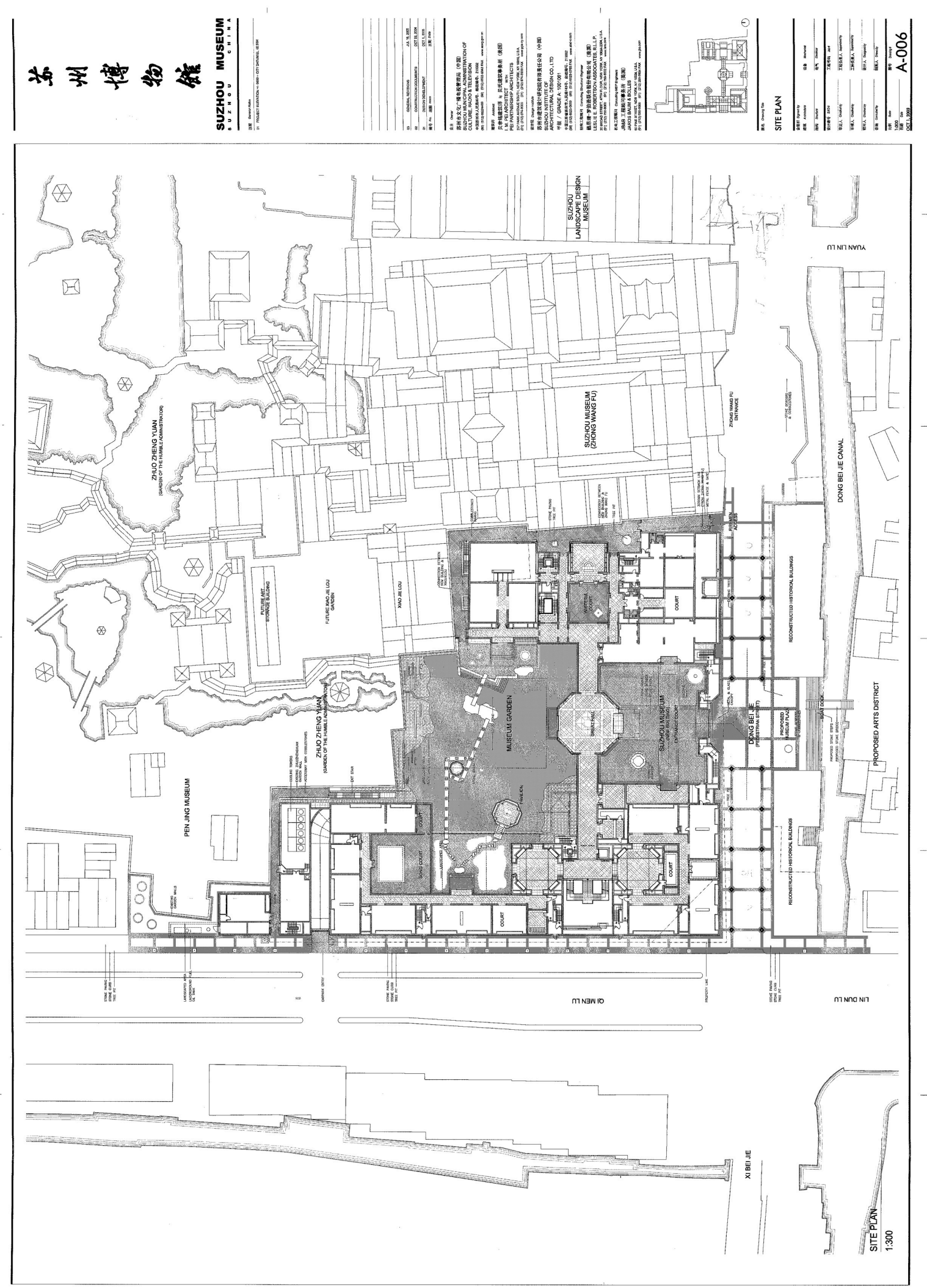


\section{Bibliographies} 2006):

Barboza, David. "I. M. Pei in China, Revisiting Roots." New York Times (10/09,

1. http://search.ebscohost.com/login.aspx?direct=true \&db=n5h\&AN=28296161\&site=eh ost-live.

Boddy, Trevor. "Im Pel." Architectural Review 232, no. 1387 (09, 2012): 102103. http://search.ebscohost.com/login.aspx?direct=true \&db=a9h\&AN=79892321\&site= ehost-live.

Cannell, Michael T. I.M. Pei : Mandarin of Modernism. 1st ed. New York: Carol Southern Books, 1995.

Collins, Jo and John Jervis. Uncanny Modernity : Cultural Theories, Modern Anxieties. Houndmills, Basingstoke, Hampshire ;New York: Palgrave Macmillan, 2008. http://www.loc.gov/catdir/enhancements/fy0809/2008000186-

b.html; http:/www.loc.gov/catdir/enhancements/fy0809/2008000186-d.html.

Deitz, Paula. "IM Pei: A Life in Architecture." Architects' Journal 231, no. 4 (02/04, 2010):

41. http://search.ebscohost.com/login.aspx?direct=true \&db=oih\&AN=48477817\&site $=$ eh ost-live.

-. "Stones, Scrolls and Scholars: Museum, Suzhou, China." Architectural Review 222, no. 1328 (10, 2007): 64-

73. http://search.ebscohost.com/login.aspx?direct $=$ true $\& d b=$ bvh\&AN $=606595 \&$ site $=$ eho st-live.

Dong, Yugan. "Prophesy and Allegory: Ieoh Ming Pei's Modern Chinese Architecture." Shi Dai Jian Zhu = Time \& Architecture no. 5 (09, 2007): 60-

65. http://search.ebscohost.com/login.aspx?direct $=$ true $\& d b=$ bvh\&AN=610101\&site $=$ eho st-live.

Frampton, Kenneth. "Towards a Critical Regionalism." In The Anti-Aesthetic, edited by Hal Foster, 16-30. Port Townsend: Bay Press, 1983.

Freud, Sigmund, David McLintock, and Hugh Haughton. The Uncanny. Penguin Classics. [Essays. English. Selections]. New York: Penguin Books, 2003. http://www.loc.gov/catdir/enhancements/fy0716/2003058102-

b.html;http://www.loc.gov/catdir/enhancements/fy0716/2003058102-d.html.

Fu, Xiaoxia. "Application of Chinese Traditional Cultural Symbol to Suzhou Museum Design." Hundred Schools in Arts no. S1 (2010): 93-94+150. 
Ivy, Robert Adams. "I.M. Pei Returns to His Family's Hometown in China and Designs the Suzhou Museum for a Sensitive, Historic Site." Architectural Record 195, no. $5(05,2007)$ :

186. http://search.ebscohost.com/login.aspx?direct=true $\& \mathrm{db}=$ bvh \&AN=600242\&site $=$ eh ost-live.

Ivy, Robery. "I.M. Pei, FAIA, on the Suzhou Museum." Architectural Record 195, no. $5(05,2007)$ : 190-

190. http://search.ebscohost.com/login.aspx?direct=true \&db=a9h\&AN=26203816\&site= ehost-live.

Ji, Cheng, Shikui Li, and Jinpeng Liu. Yuan Ye. Beijing Shi: Zhonghua shu ju, 2011.

Jing, Xiaolei. "Mixed Motives." Beijing Review 51, no. 30 (07/24, 2008): 2424. http://search.ebscohost.com/login.aspx?direct $=$ true $\& d b=a 9 h \& A N=33933067 \&$ site $=e$ host-live.

Jodidio, Philip and Janet Adams Strong. I.M. Pei : Complete Works. New York: Rizzoli, 2008.

Keswick, Tessa. "Cultural Renaissance in China's Venice.(Suzhou)." Literature Resource Center (Nov.11, 2006).

Learning from Light the Vision of I.M. Pei. Directed by Landin, Bo., Van Wagenen, Sterling,, Landin, Marianne., Van Wagoner, Mark., Slickrock Films., Qatar Museums Authority.,Films Transit International Inc.,. [Montreal, Quebec]: Films Transit International Inc., 2012.

Leach, Andrew. What is Architectural History?. What is History? Series. Cambridge, UK ;Malden, MA: Polity, 2010.

Liao, Xiaodong. 贝聿铭传=Beiyuming Zhuan. Wuhan: Hubei People's Press, 2008.

Luo, Bing. "The Analysis and Think on the New Suzhou Museum." Arts Exploration no. 03 (2007): 123-125.

Pei, I. M. and Robert Adams Ivy. "At the Twilight of His Career, I.M. Pei shows Few Signs of Slowing Down." Architectural Record 192, no. 6 (06, 2004):

204. http://search.ebscohost.com/login.aspx?direct=true $\& d b=$ bvh \&AN=557064\&site $=$ eh ost-live.

Pei, I. M. and Gero von Boehm. Conversations with I. M. Pei : Light is the Key. Munich ;New York: Prestel, 2000.

Pei, Lizhong (Sandi). Interviewed by Huang Chenying. Personal interview. New York City, October 24, 2013. 

$71-$

Perlmutter, Harry. "Im Pei's Active Retirement." Art AsiaPacific no. 53 (May, 2007):

71. http://search.ebscohost.com/login.aspx?direct=true\&db=hlh\&AN=24909694\&site=eh ost-live.

Reid, Aileen. I.M. Pei. New York: Crescent Books, 1995.

I. M. Pei: Building China Modern. Directed by Shirley, Eugene B., Anne Makepeace, Brian Funck, et al. S.L.: PACEM Distribution International, LLC ;Oley, PA, 2010.

Vidler, Anthony. The Architectural Uncanny : Essays in the Modern Unhomely. Cambridge, Mass.: MIT Press, 1992.

Wiseman, Carter. I.M. Pei : A Profile in American Architecture. New York: H.N. Abrams, 1990.

Xu, Ning, Fumin Gao, and Xiaoying Ni. Bei Yuming Yu Suzhou Bo Wu Guan =I.M. Pei. and Suzhou Museum. Suzhou: Gu Wu xuan chu ban she, 2007.

Xu, Yinong. The Chinese City in Space and Time : The Development of Urban Form in Suzhou. Honolulu: University of Hawai'i Press, 2000.

Yan, He. "I.M. Pei and His "Lovely Youngest Daughter."." China Today 56, no. 11 $(11,2007): 42-$

45. http://search.ebscohost.com/login.aspx?direct $=$ true $\& d b=a 9 h \& A N=27246982 \&$ site $=e$ host-live.

Zhang, Jun. "Discussion on the Tendency of Neo-Vernacularism in Landscape Design Combined with the Courtyard Design in New Suzhou Museum." Huazhong Architecture no. 01 (2008): 124-128.

Zhang, Ke and Hong Zhang. "Urban Leap Forward and I. M. Pei's Suzhou Museum." World Architecture no. 04 (2007): 119.

Zhang, Xin, Xuemei Lu, and Xiaoting Xie. "Inheritance, Innovation and Integration-Construction and Exhibition Design of New Suzhou Museum." Art \& Design no. 03 (2009): 27-30.

Zhang, Xin and Suzhou bo wu guan. Suzhou Museum. Beijing; London: Great Wall Publishers ; In collaboration with London Editions, 2007.

Zhu, Yuhui. "A Typical Misinterpretation of Architectural Heritage-The Pity of Suzhou Museum." Proceedings of International Conference on Chinese Architectural History IV (2003): 582-583. 


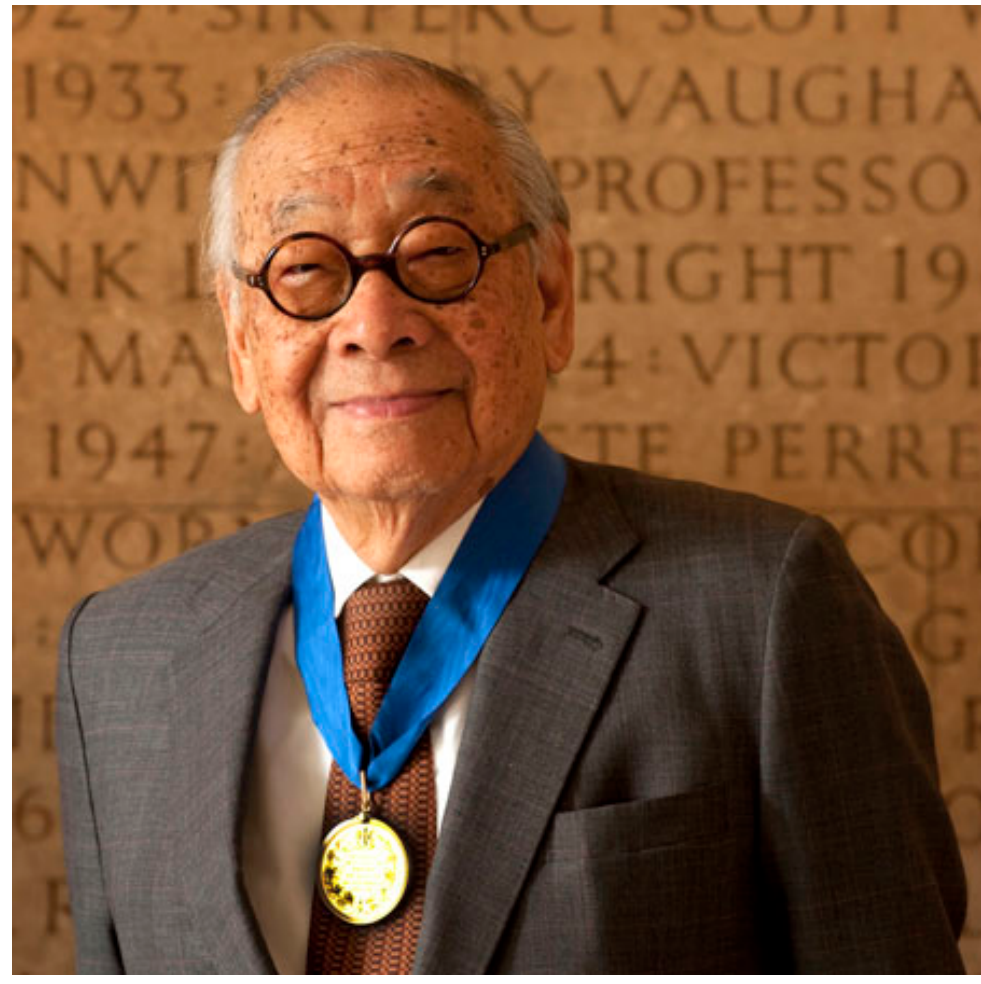

Figure 1 I.M. Pei, receiving the Royal Gold Metal for architecture in London, 2010.

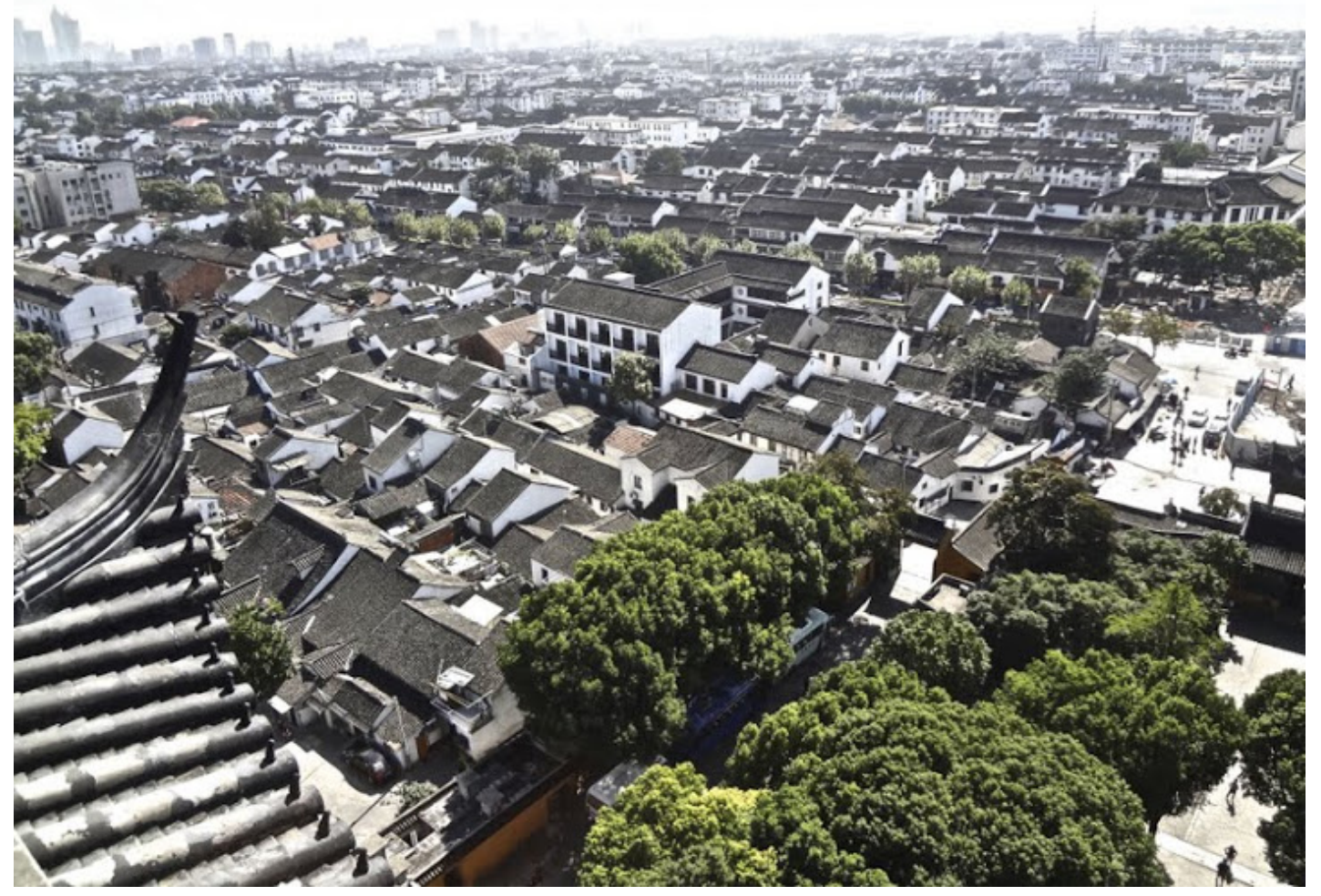

Figure 2 Skyline View of old inner city of Suzhou from Baoen Pagoda. 


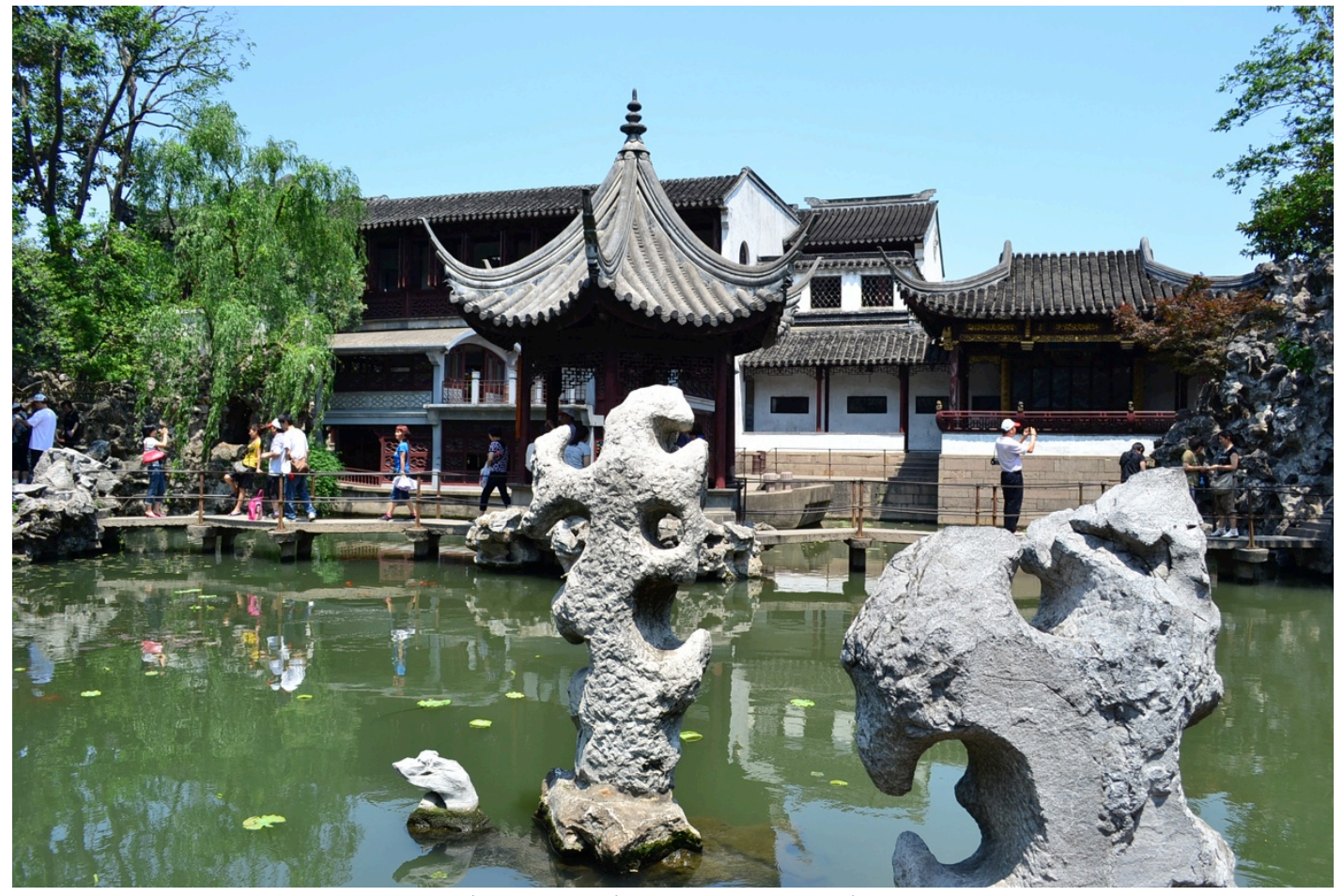

Figure 3 Lion Grove Garden.

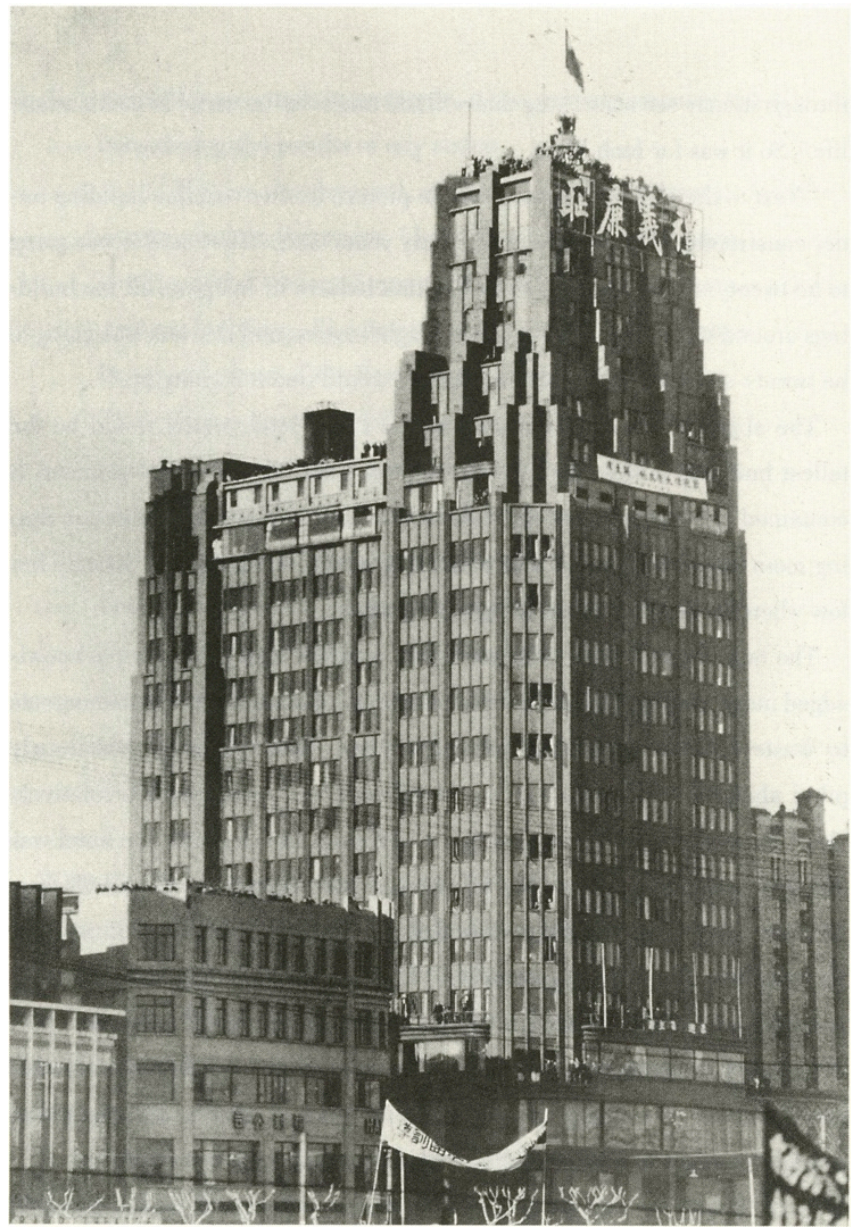

Figure 4 Park Hotel, Shanghai. 


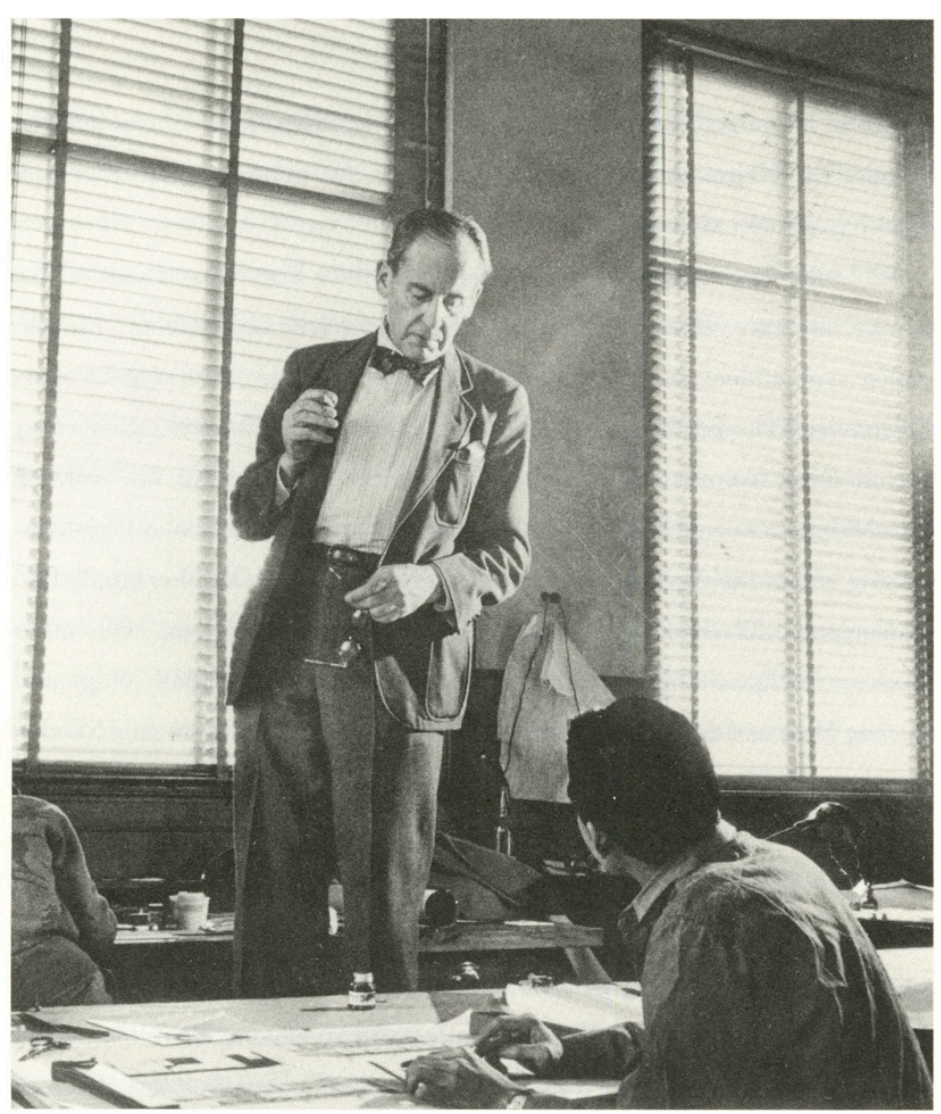

Figure 5 I.M. Pei and Walter Gropius.

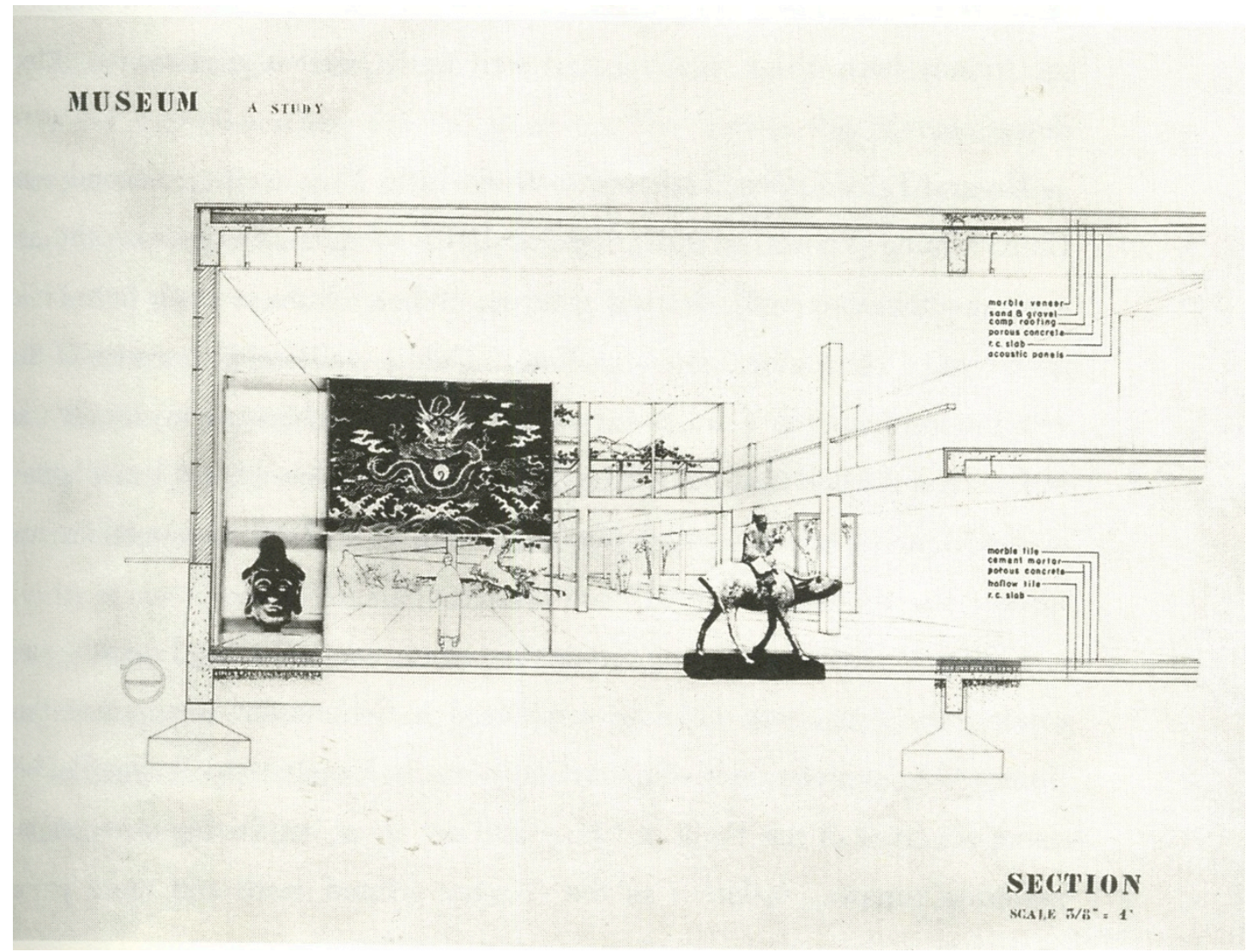

Figure 6 Shanghai Art Museum, Pei’s thesis. 


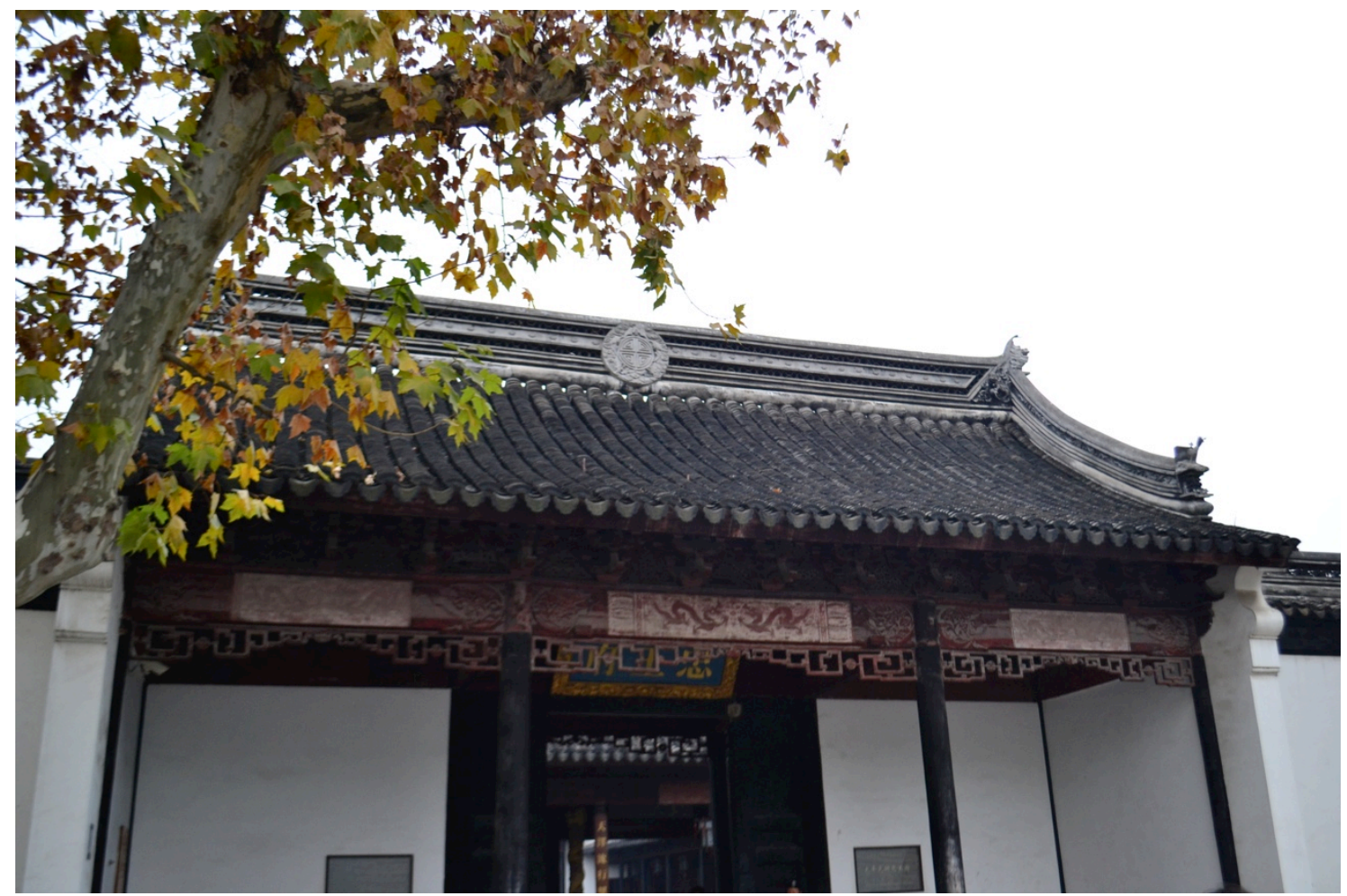

Figure 7 Entrance of the Prince Zhong's Mansion.

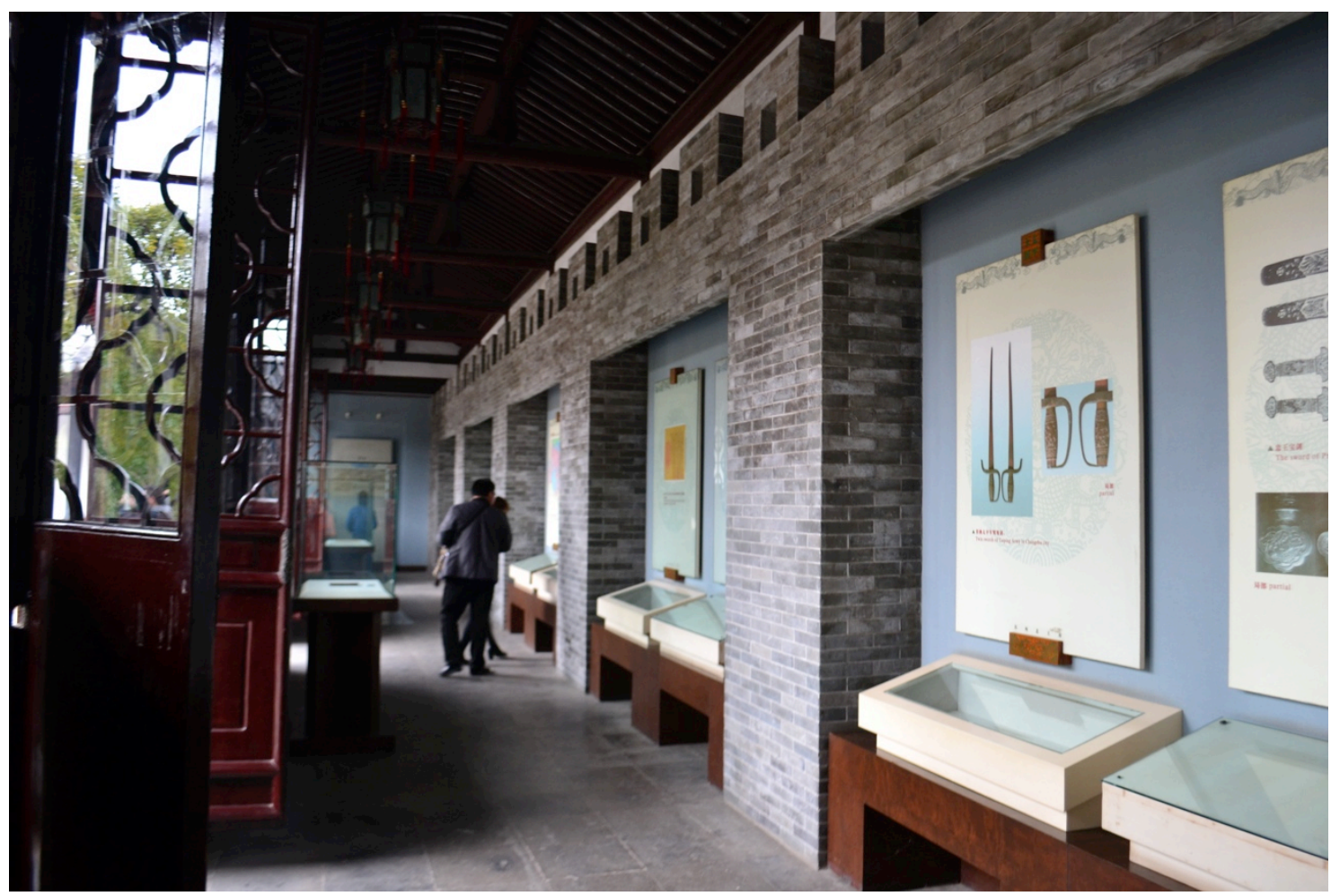

Figure 8 Exhibitions in the Prince Zhong's Mansion. 


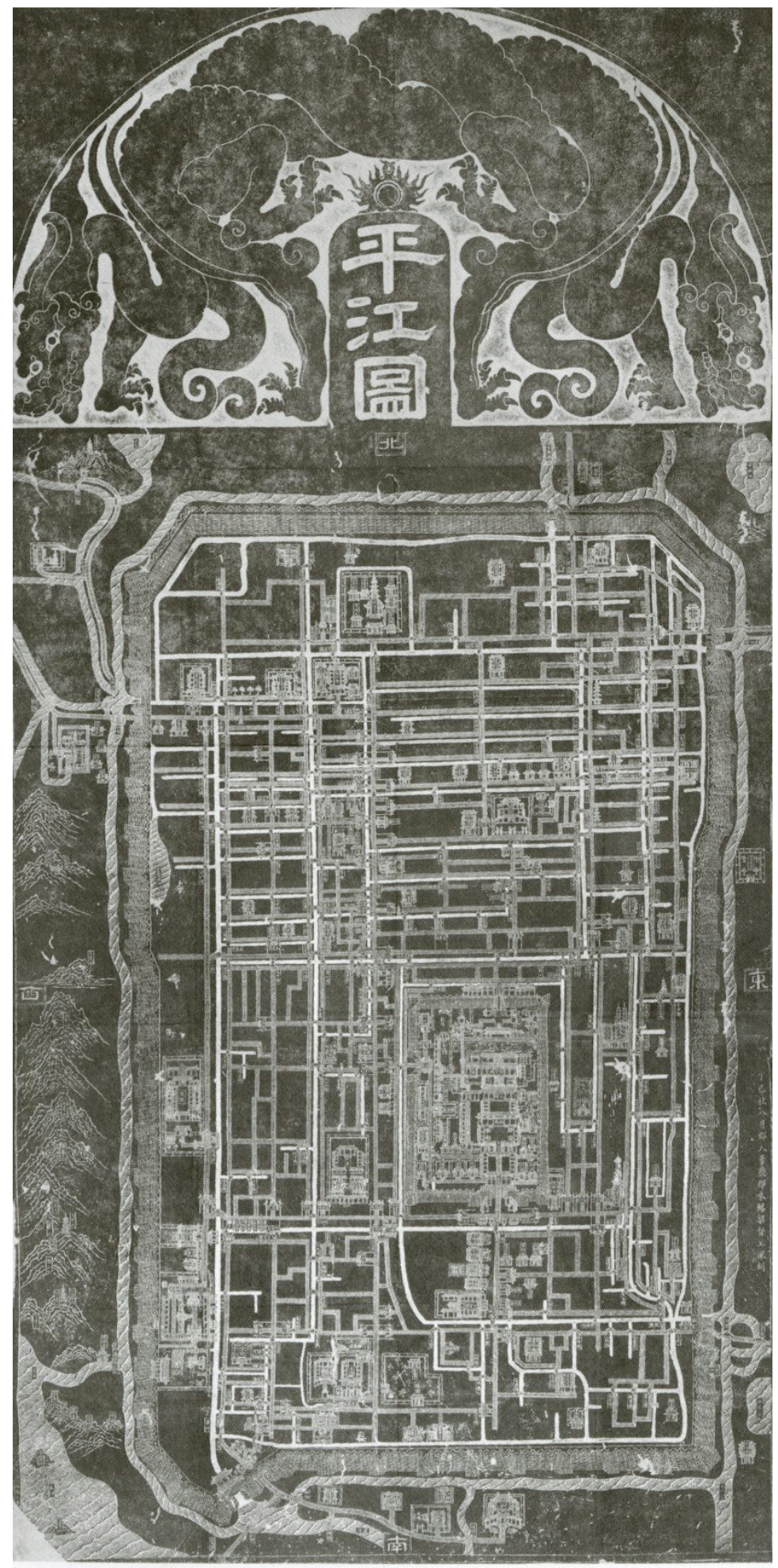

Figure 9 Old Suzhou (Pingjiang) Map. 


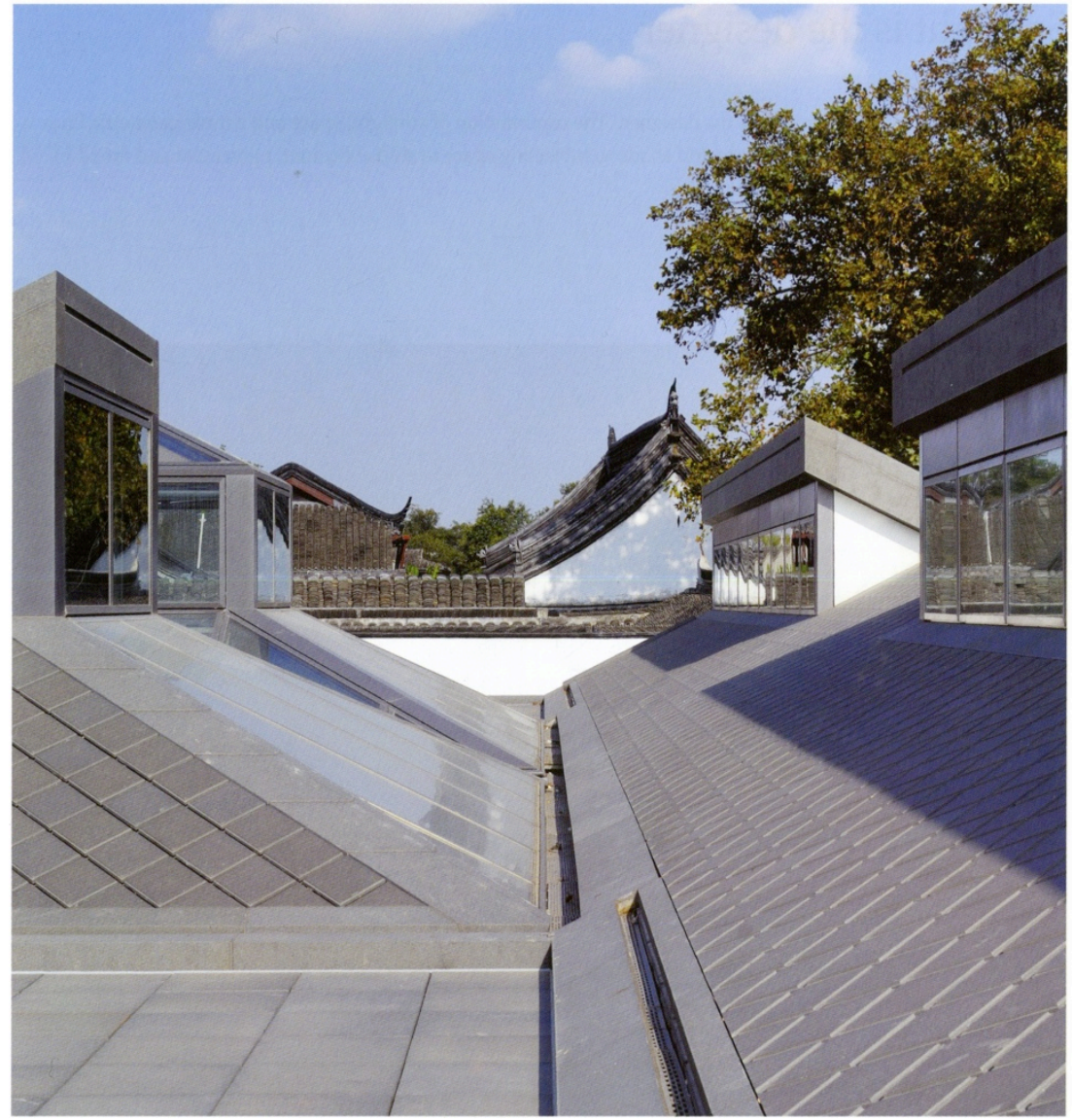

Figure 10 Comparison of the ancient roofs and the new Suzhou Museum roofs.

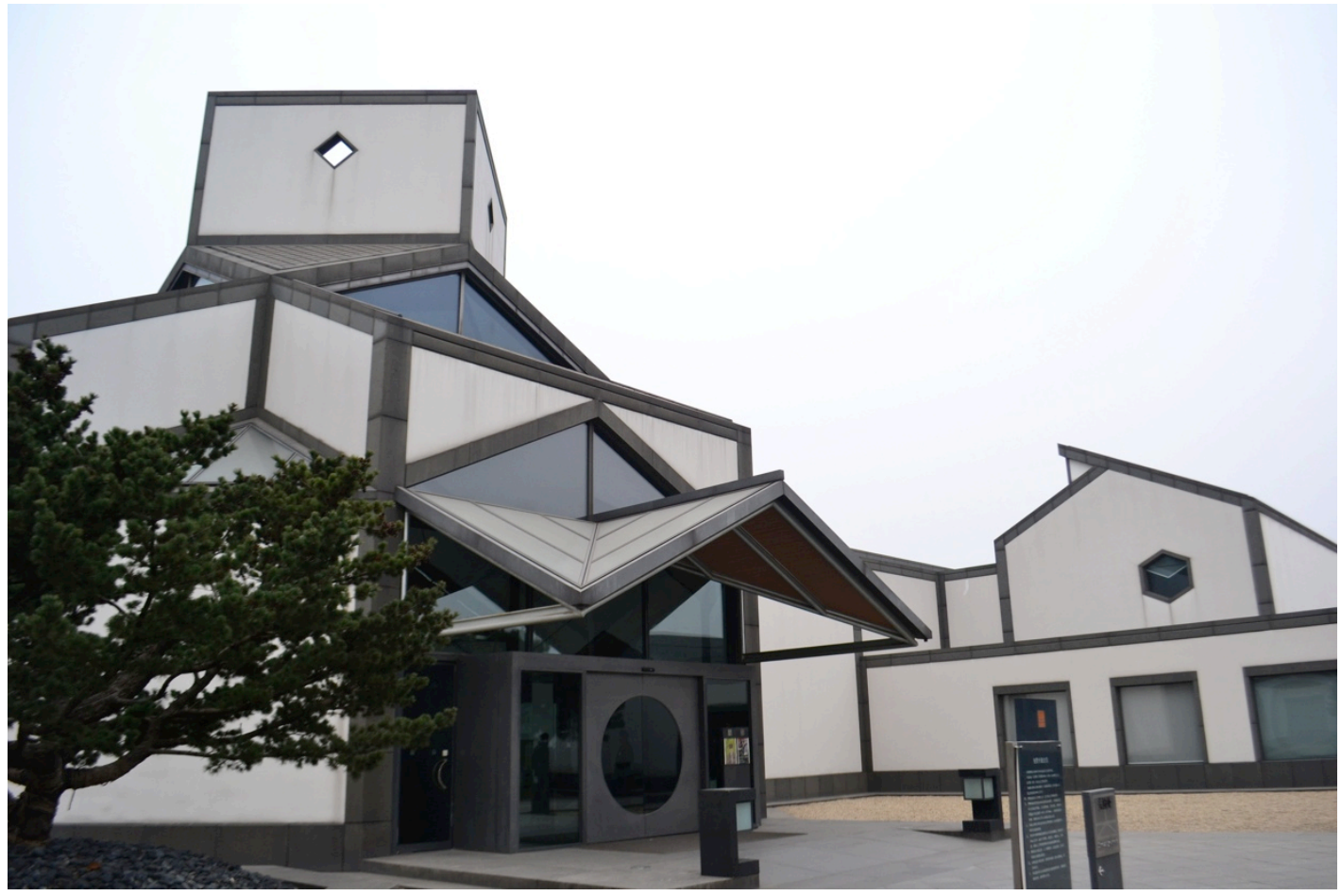

Figure 11 Entrance of the Suzhou Museum. 


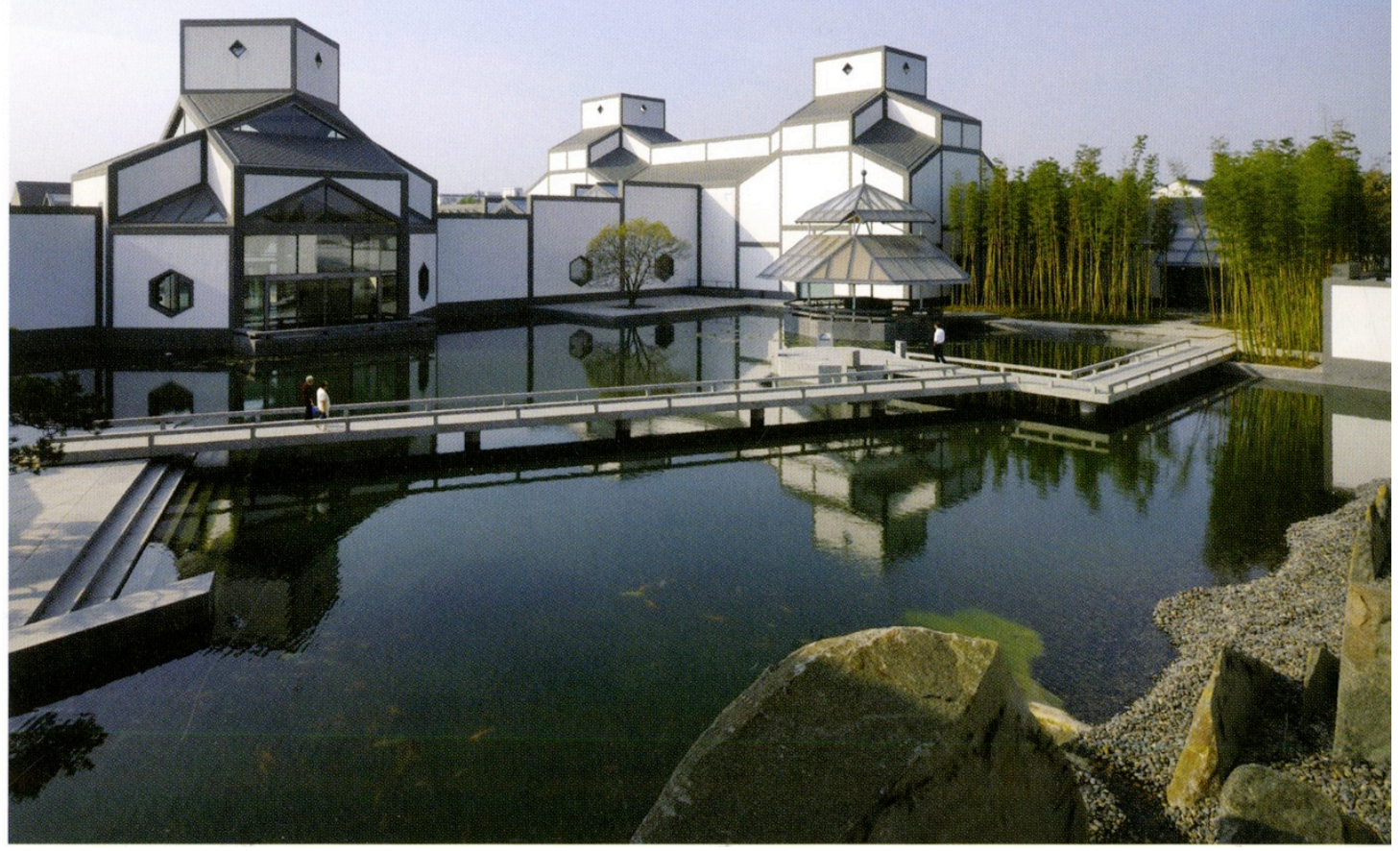

Figure 12 Garden view of the Suzhou Museum

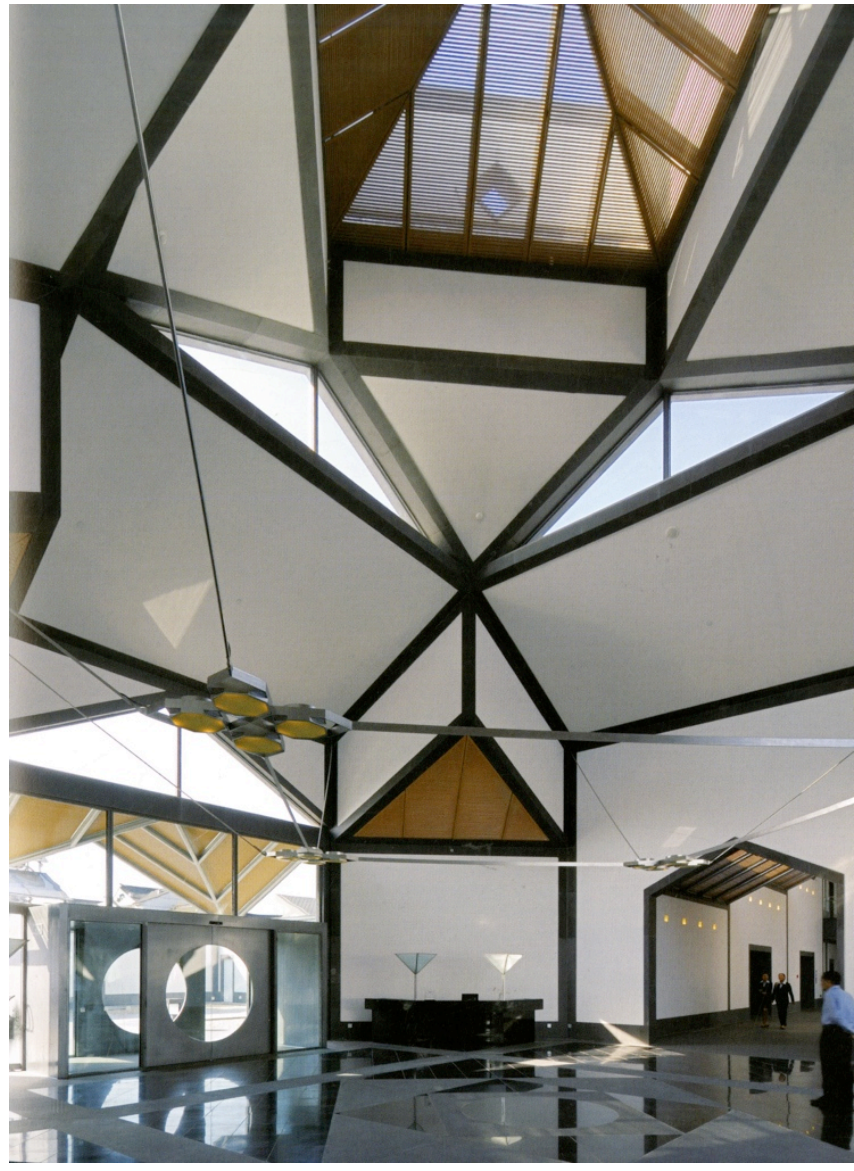

Figure 13 Lobby of the Suzhou Museum. 


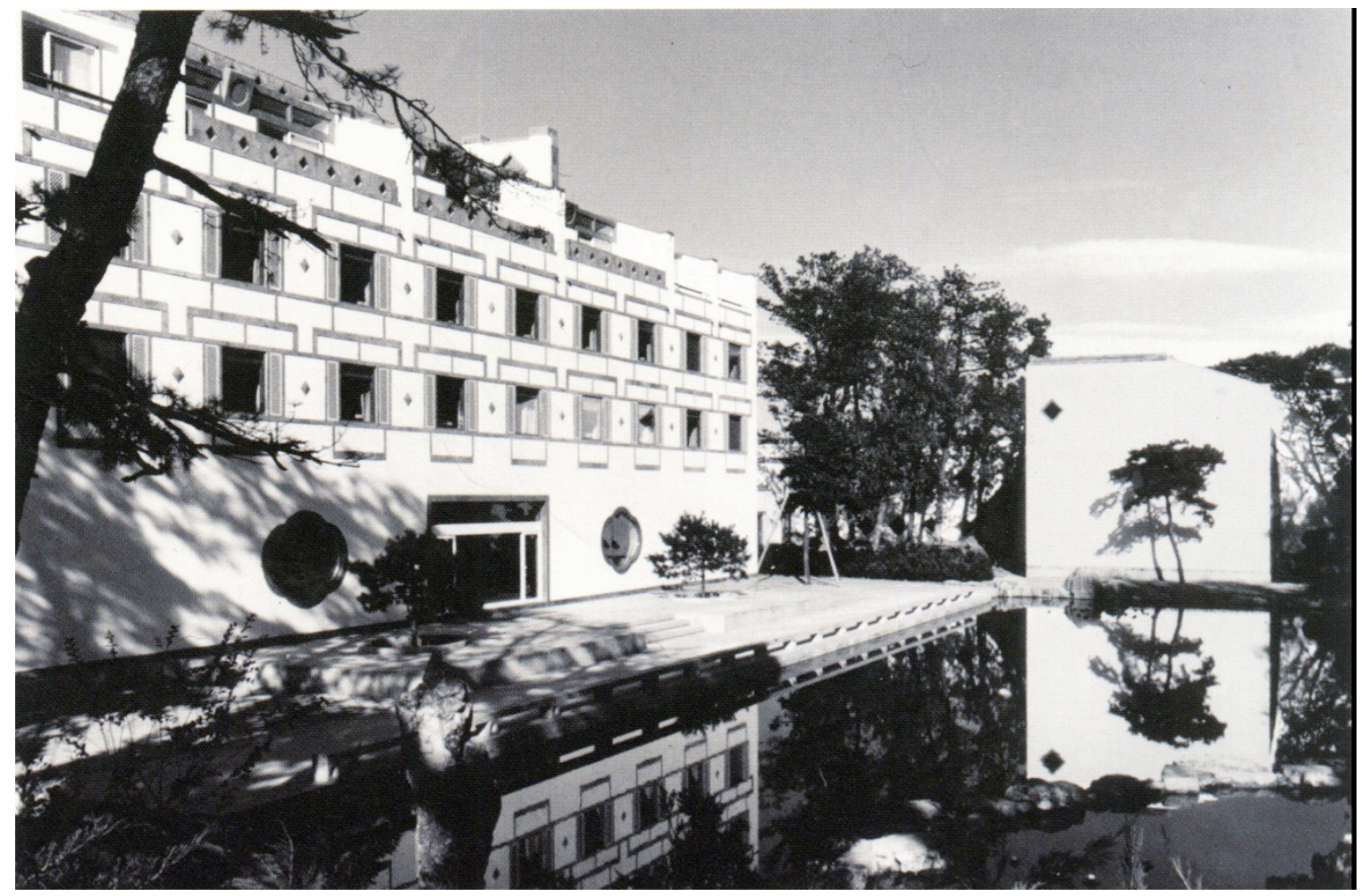

Figure 14 Fragrant Hill Hotel, Garden Façade, Beijing.

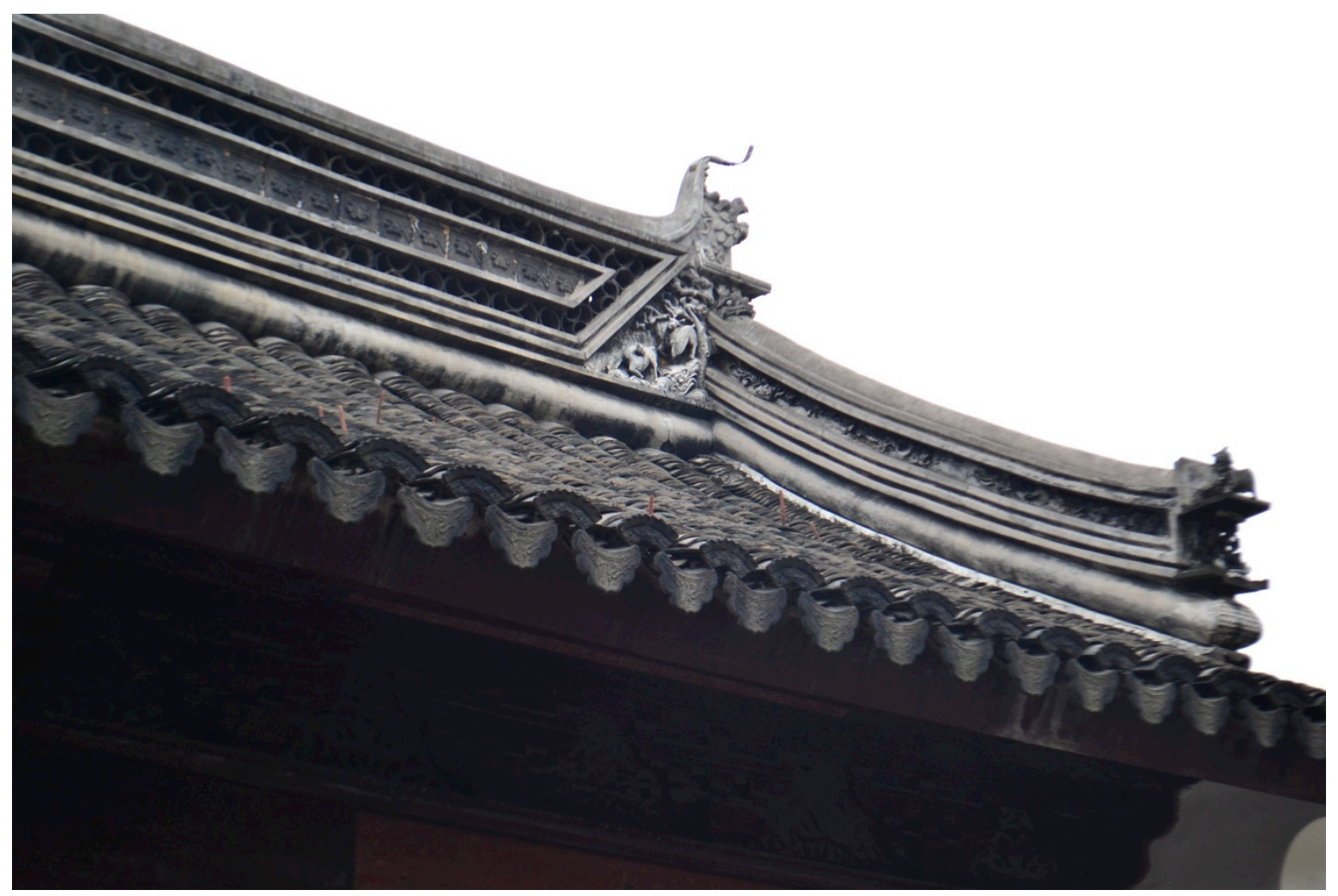

Figure 15 Eave structure of the Prince Zhong's Mansion. 


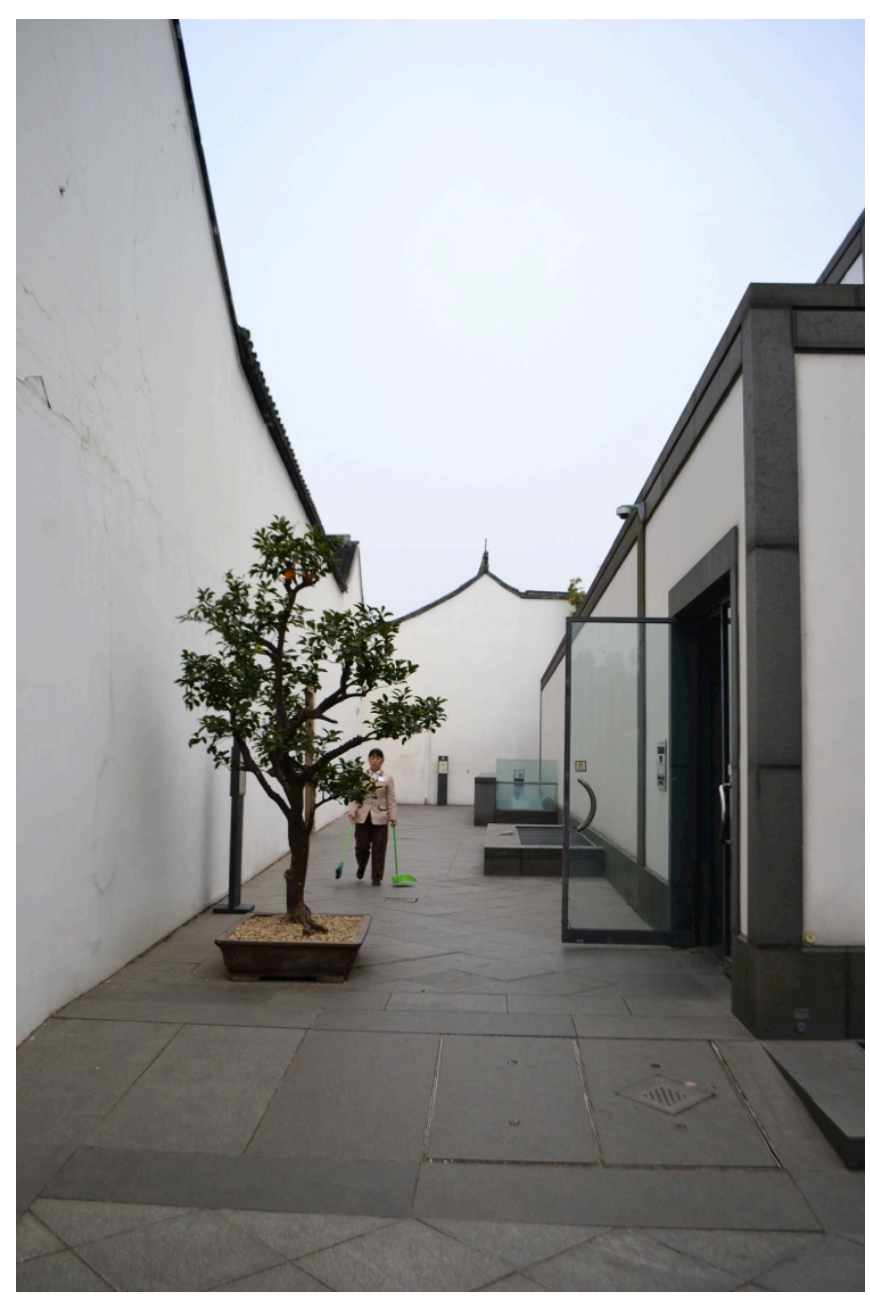

Figure 16 Walkway between the Suzhou Museum and ancient structures.

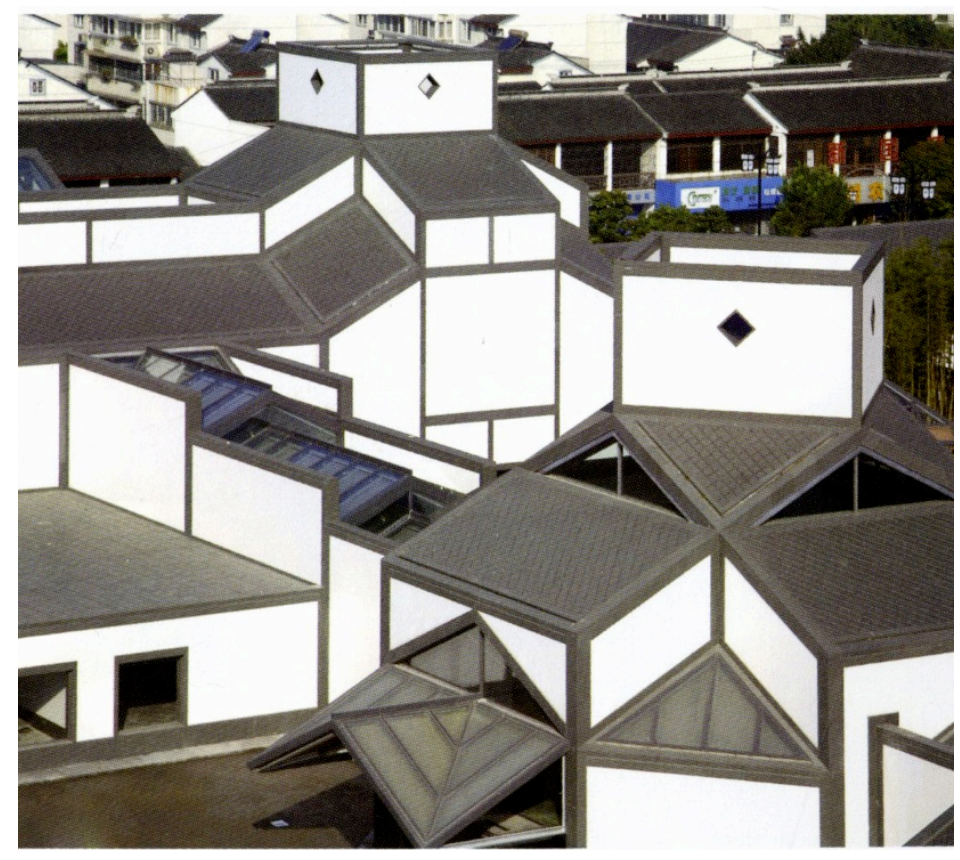

Figure 17 Roof of the Suzhou Museum. 


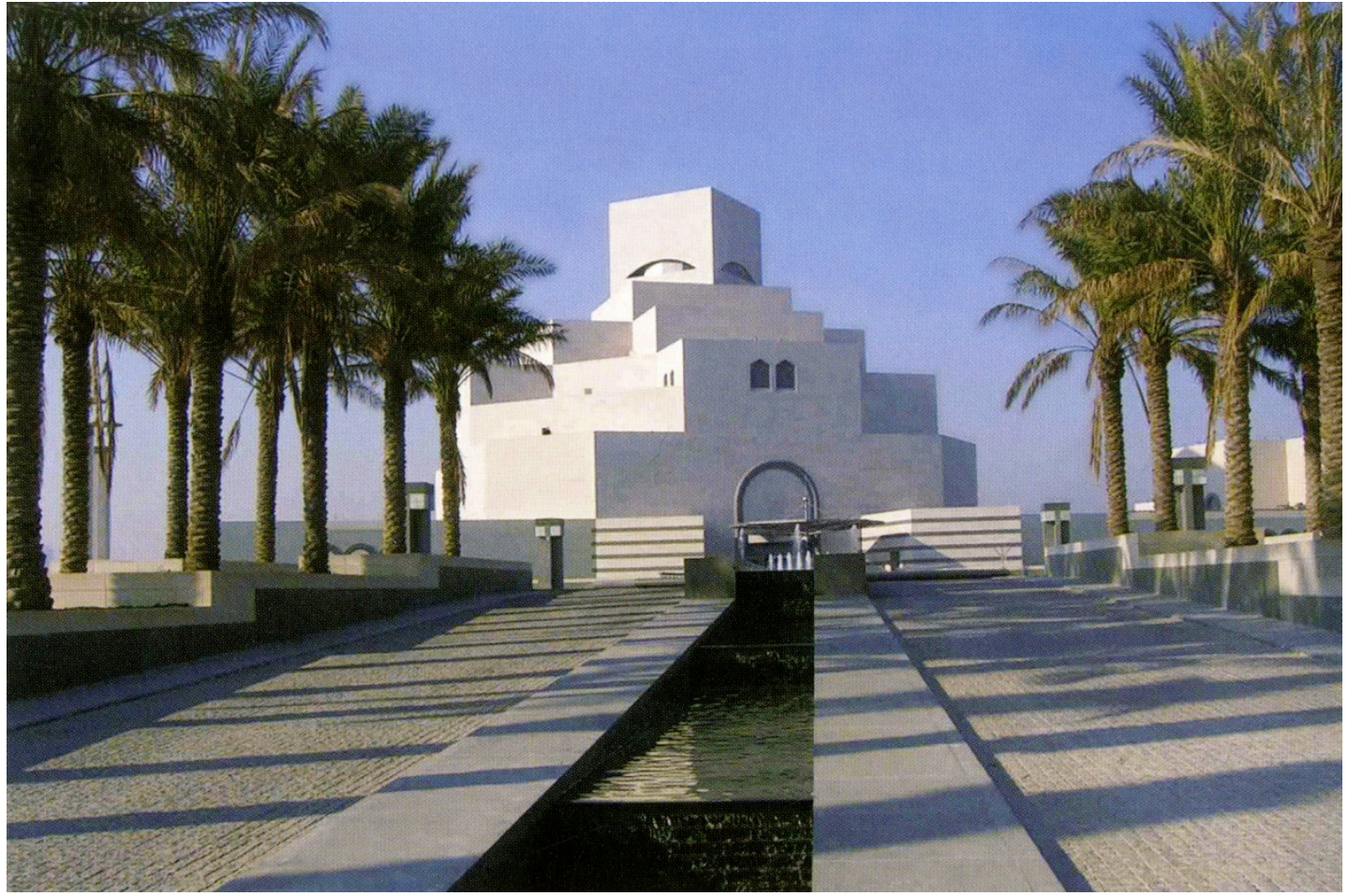

Figure 18 Museum of Islamic Art, Doha.

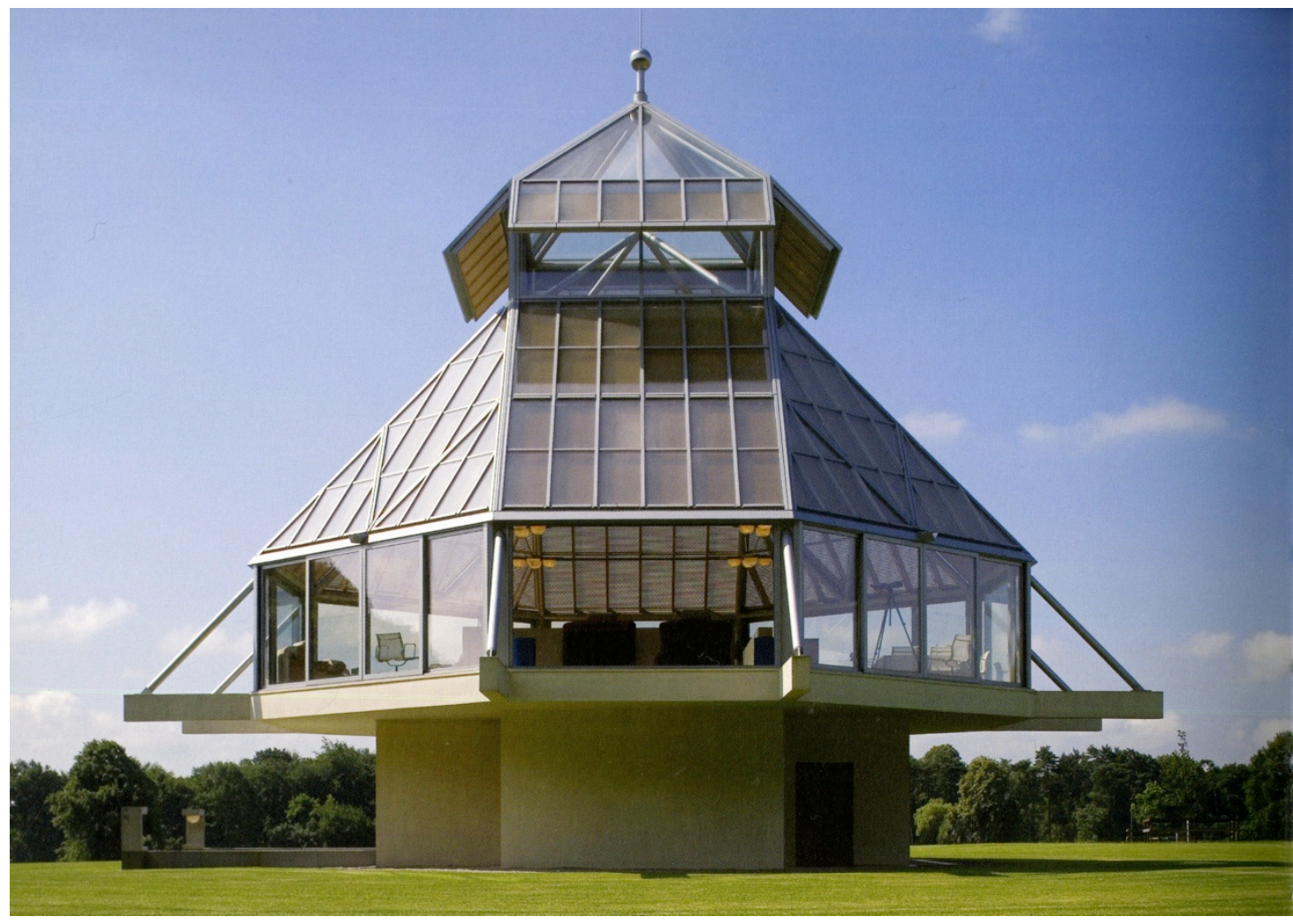

Figure 19 Oare Tea Pavilion, England. 


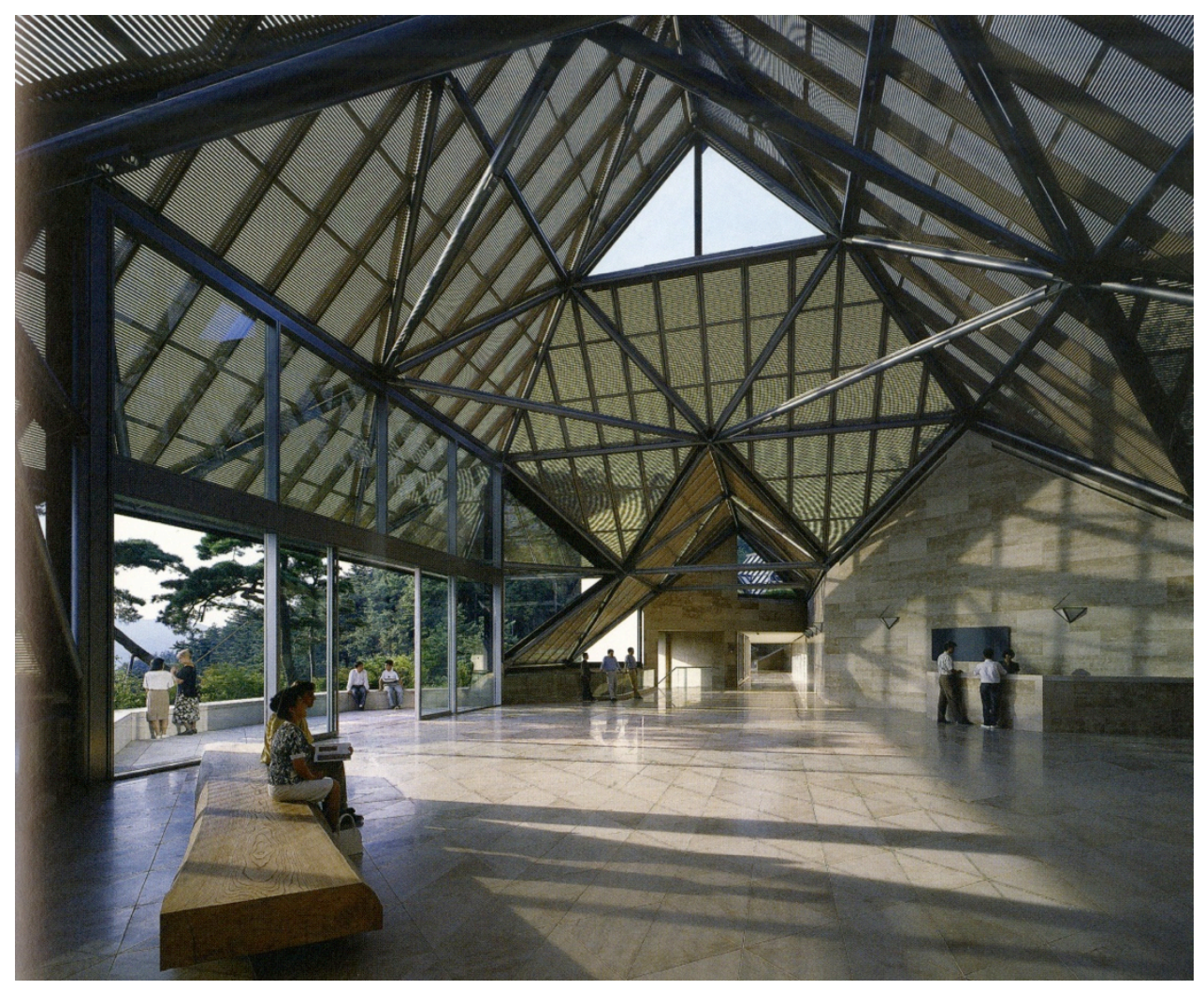

Figure 20 Lobby of Miho Museum, Japan.

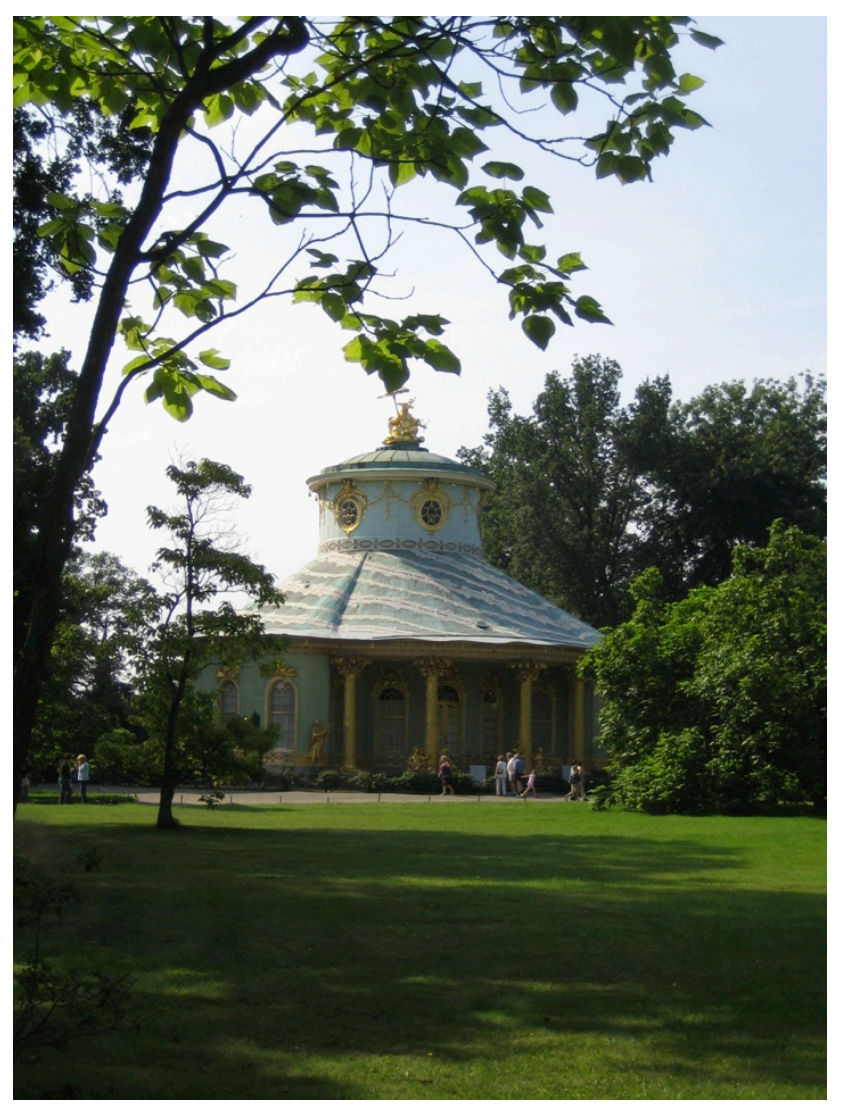

Figure 21 The Chinoiserie Tea House, Sanssouci Summer Palace, Germany. 


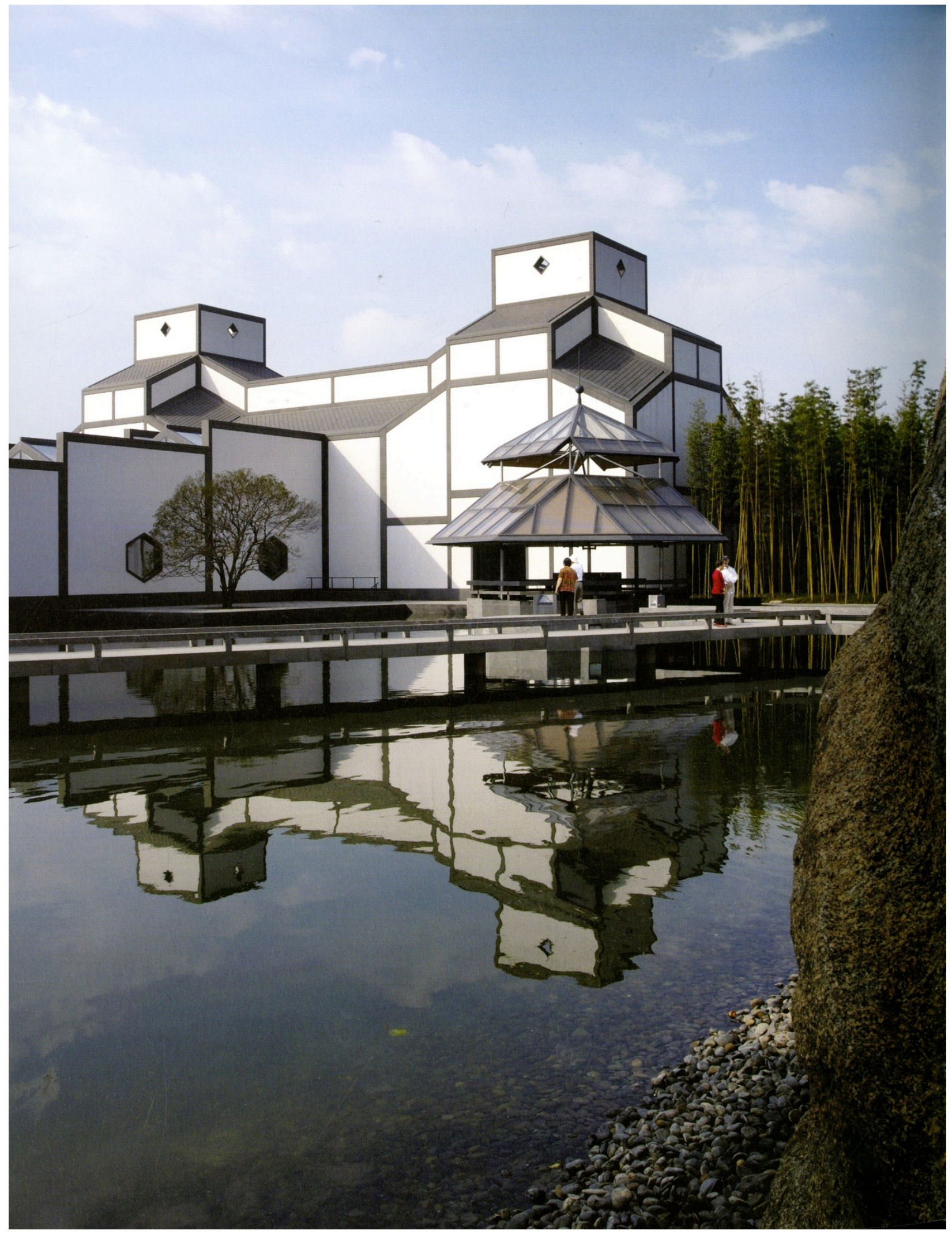

Figure 22 Ting structure in the Suzhou Museum garden. 


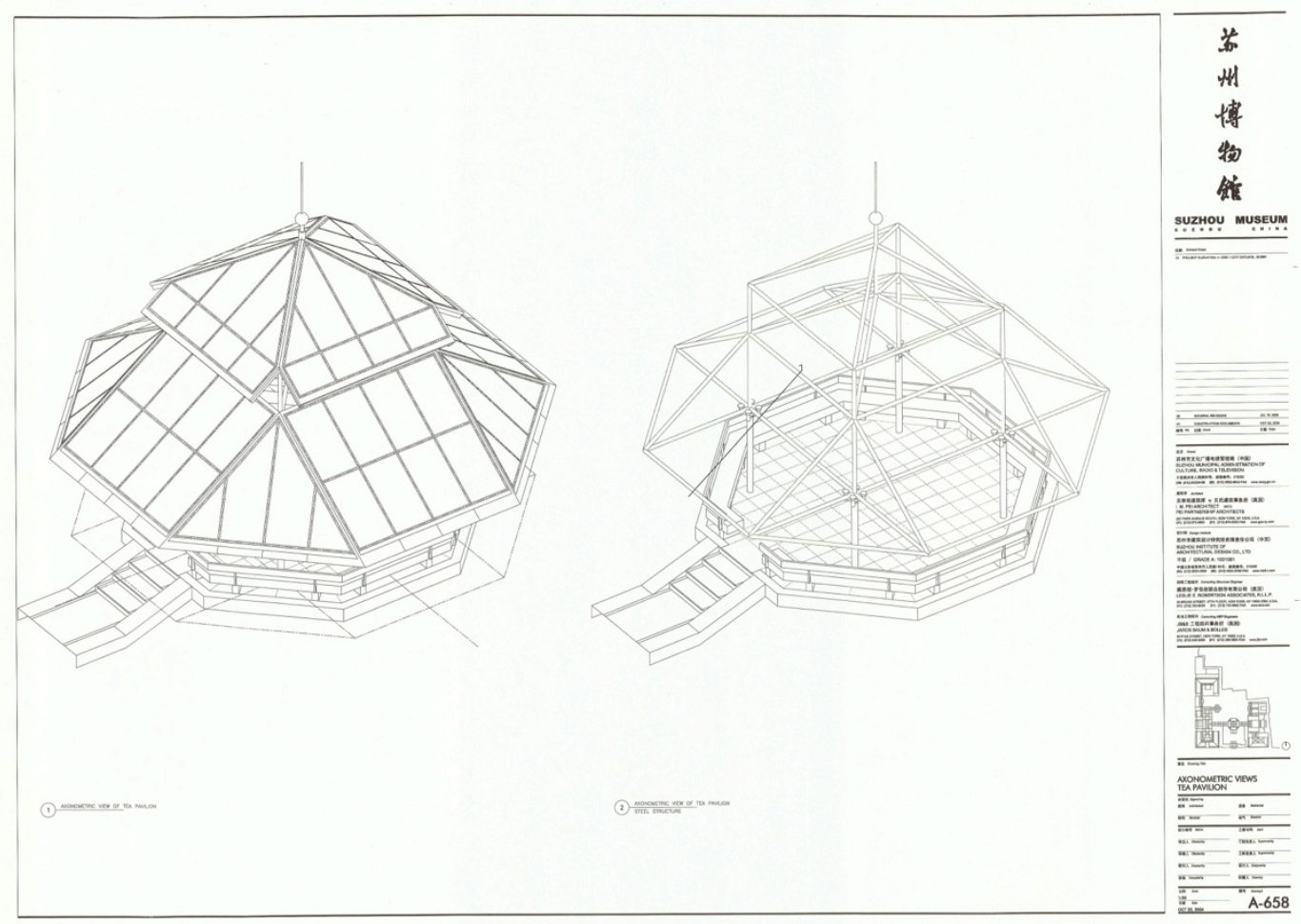

Figure 23 Ting structure of the Suzhou Museum, CAD drawing.

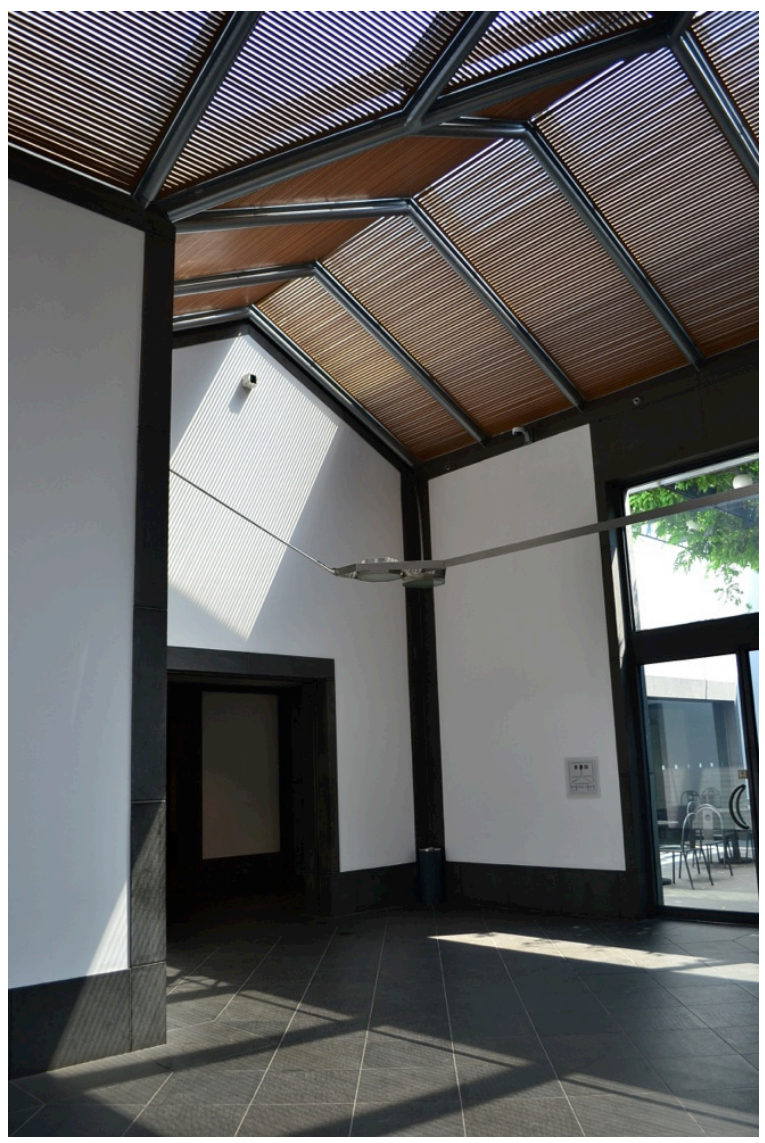

Figure 24 Interior roof screen of the Suzhou Museum 


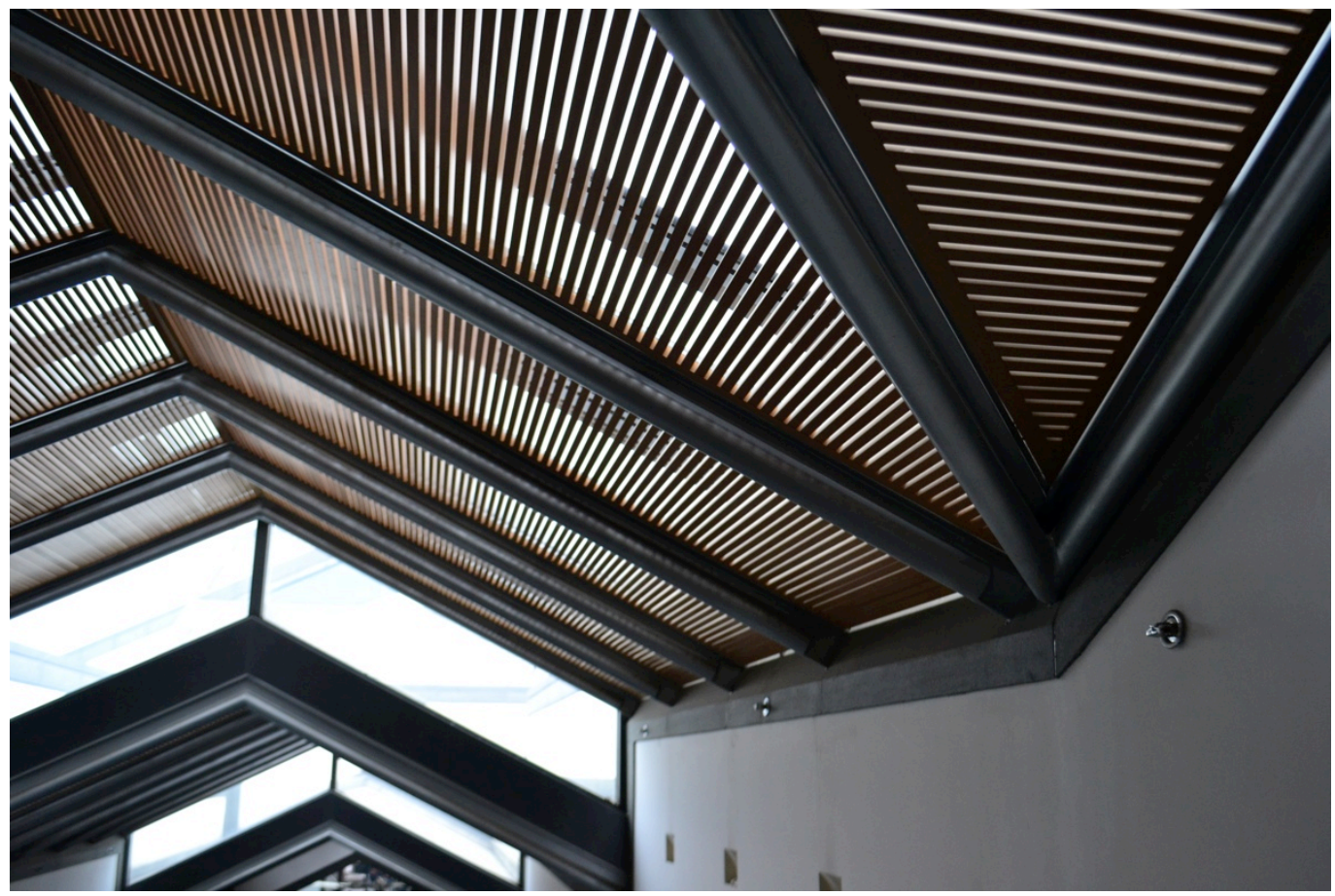

Figure 25 Interior roof screen of the Suzhou Museum

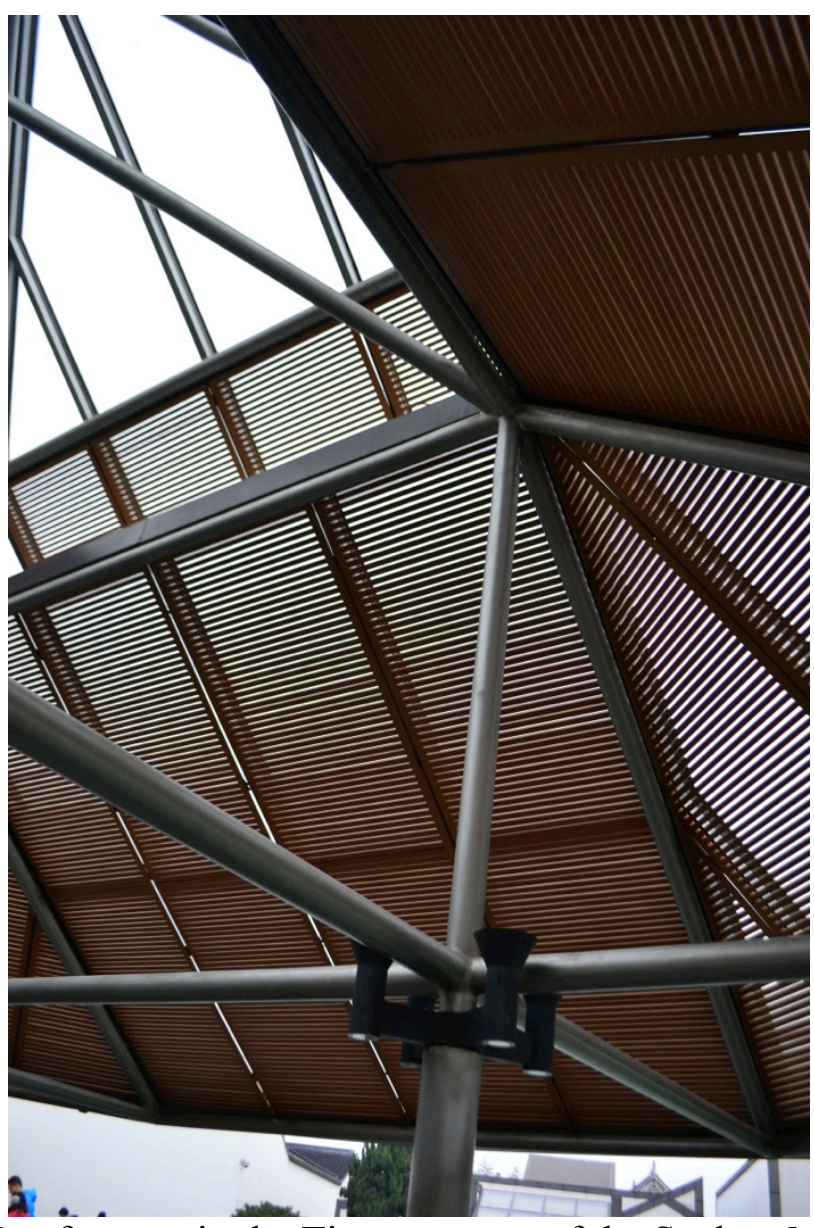

Figure 26 Roof screen in the Ting structure of the Suzhou Museum 


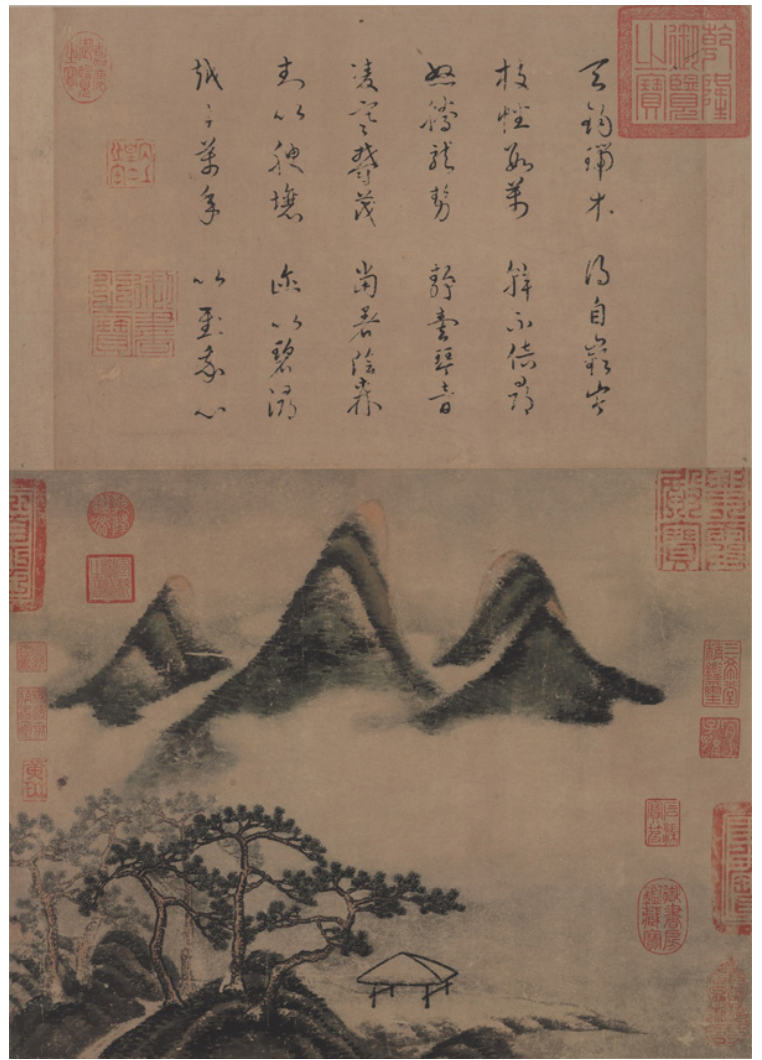

Figure $27 \mathrm{Mi} \mathrm{Fu} \mathrm{“Auspicious} \mathrm{Pines} \mathrm{in} \mathrm{Spring} \mathrm{Mountains”,} \mathrm{showing} \mathrm{typical} \mathrm{Mi} \mathrm{Fu's} \mathrm{landscape}$ traditional Chinese ink painting.

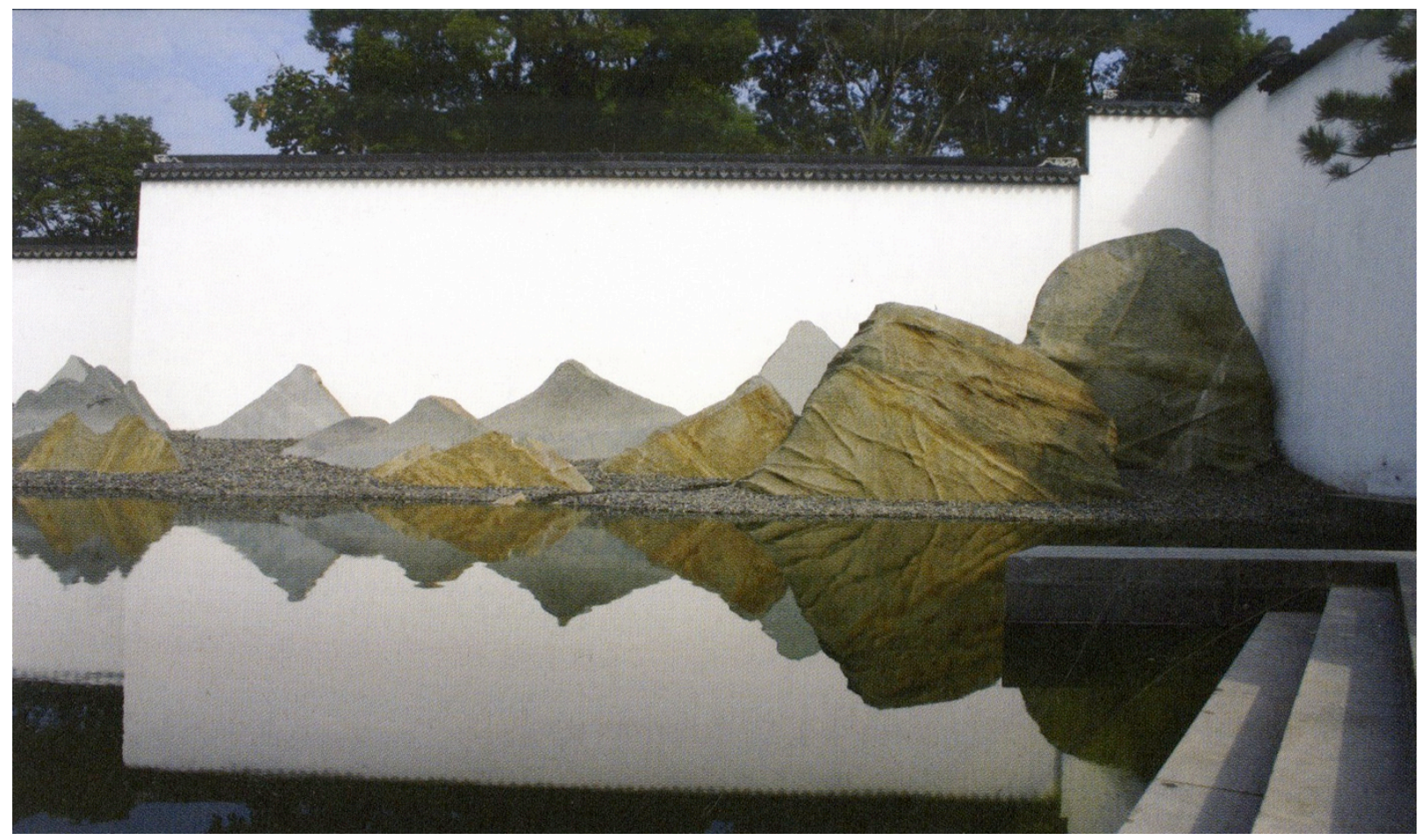

Figure 28 Rockery painting in the Suzhou Museum garden. 


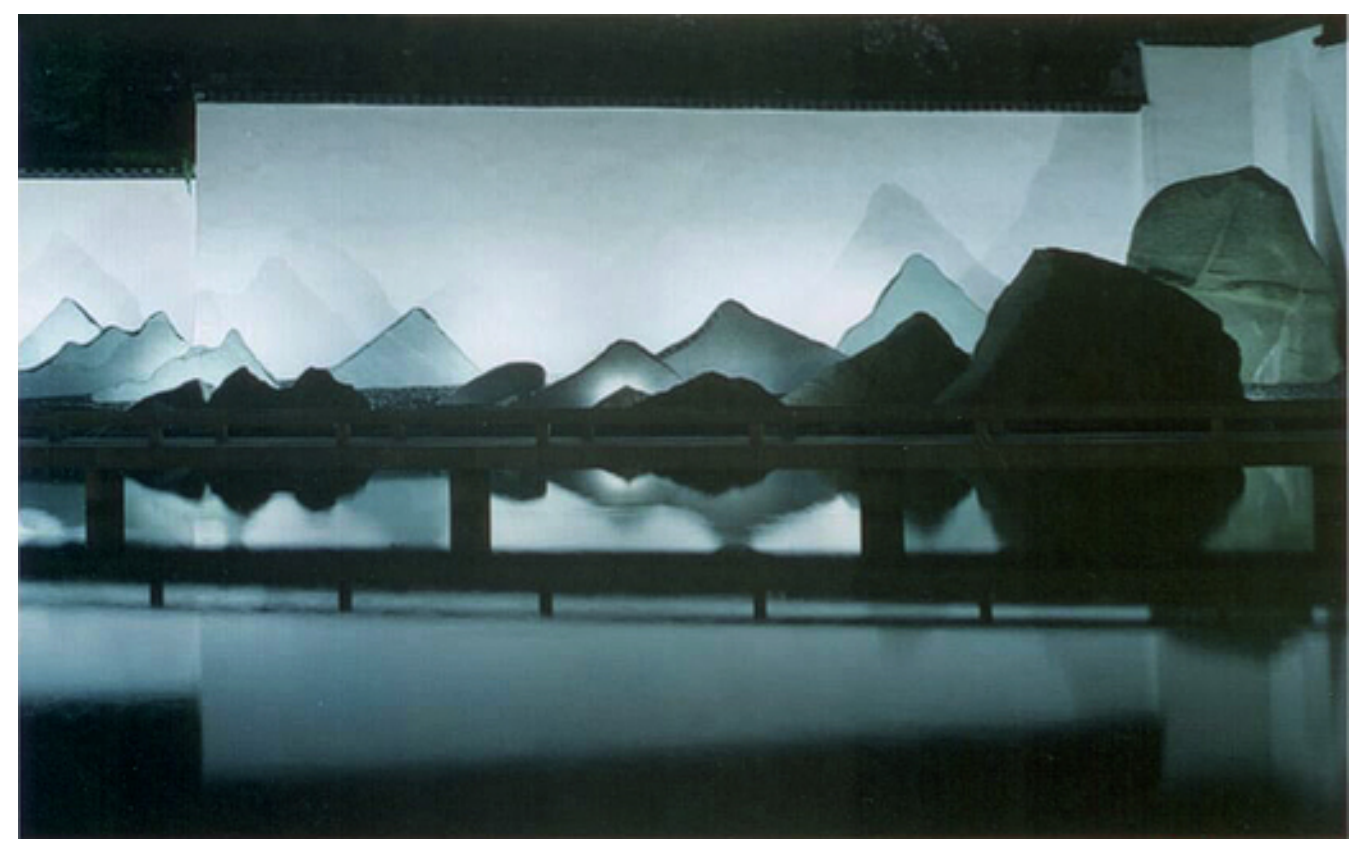

Figure 29 Light effects at night of the rockery painting in the Suzhou Museum garden.

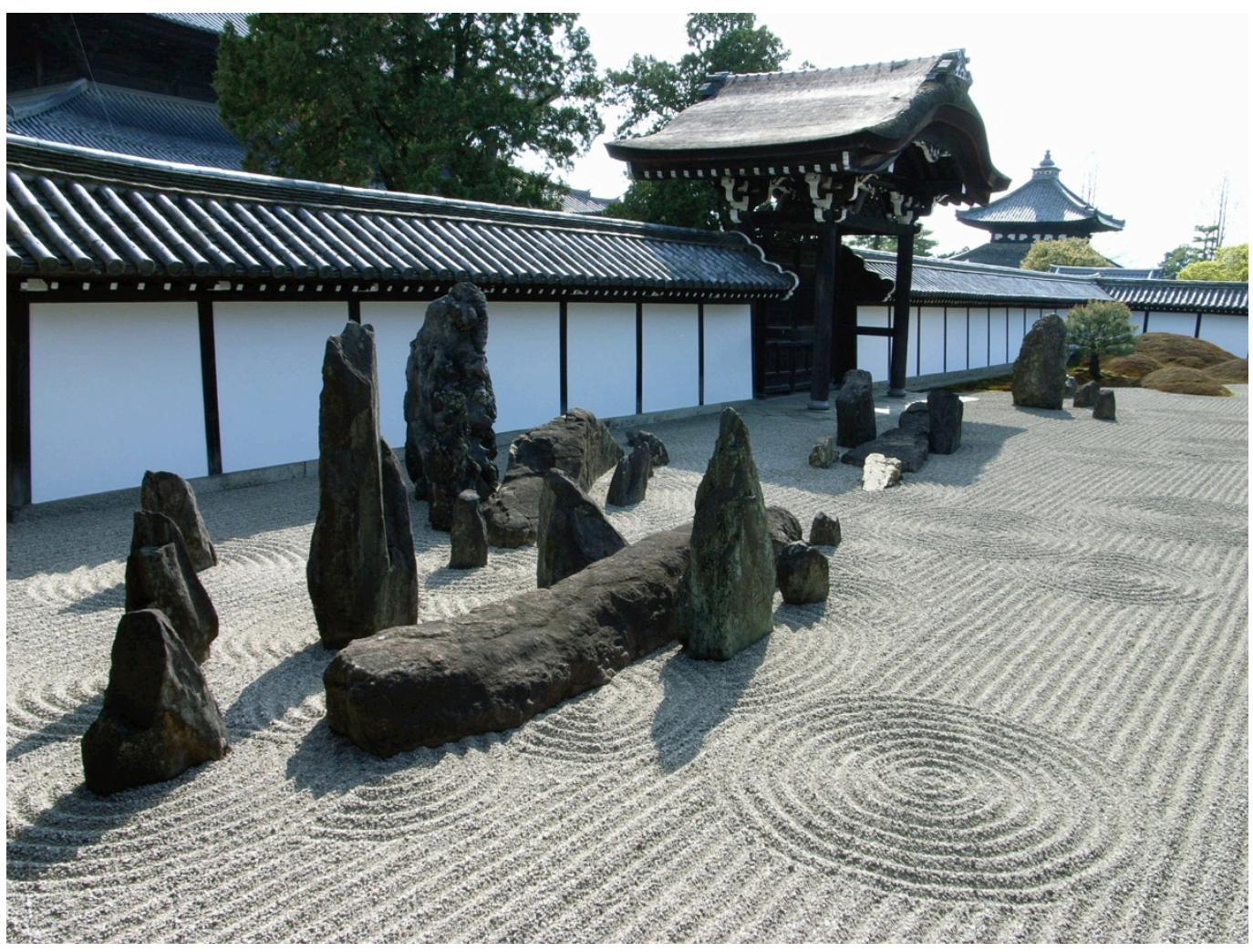

Figure 30 Japanese Rock Garden. 